\title{
LOS MAESTROS DE PRIMERAS LETRAS EN LA PROVINCIA DE MADRID A TRAVÉS DEL CATASTRO DE ENSENADA (1749-1756)
}

\author{
Literacy teachers in Madrid province through "Catastro \\ de Ensenada» (1749-1756)
}

\section{Nuria González Barrero*}

Fecha de recepción: 20/11/2014 • Fecha de aceptación: 09/06/2015

Resumen: El presente trabajo pretende ofrecer una primera aproximación a la realidad de la situación de los maestros de primeras letras y, en menor medida, a la de los preceptores de gramática, en la antigua Provincia de Madrid mediante la información que nos proporcionan los Libros de Estados Generales del Catastro de Ensenada (realizado entre 1749 y 1756). Por ello, a través de las Respuestas generales que nos proporciona el Catastro, hemos analizado la distribución de los maestros de primeras letras en las villas, pueblos y lugares de Madrid, las retribuciones de los mismos, los oficios que conjuntamente ejercían y la consideración social que tenían. Además, todos estos datos han sido comparados con otros oficios que se ejercían en Madrid para conocer mejor la situación de los maestros y poder tener una idea más aproximada y que se ajuste más a la realidad de los mismos a mediados del siglo XVIII. De igual forma, la situación económica y social de los maestros de primeras letras y de los preceptores de gramática en la provincia de Madrid ha sido comparada con la situación de maestros y preceptores en otras provincias del territorio español, en las que también se realizó el Catastro de Ensenada.

Palabras clave: Educación primaria. Maestros. Catastro de Ensenada. Estadística escolar. Siglo XVIII.

\footnotetext{
$\S$ Agradezco a la profesora Concepción Camarero su ayuda y apoyo ofrecidos para que este trabajo saliera adelante. También al profesor Félix Labrador por creer en mí y por toda la ayuda que me brinda. Este artículo ha sido premiado al mejor trabajo de investigación en la modalidad de Ciencias de la Educación por el Consejo Social de la Universidad Rey Juan Carlos. Se inserta dentro de una beca de colaboración del Ministerio de Educación, Cultura y Deportes para estudiantes en departamentos universitarios (curso académico 2012-2013).

* Universidad Rey Juan Carlos. Facultad de Ciencias Jurídicas y Sociales. Dpto. de Ciencias de la Educación, el Lenguaje, la Cultura y las Artes, Ciencias Histórico-Jurídicas y Humanísticas y Lenguas Modernas. Paseo de Artilleros, sn, 28032. Madrid. España.nuria91.gb@gmail.com
}

Cómo citar este artículo: González Barrero, Nuria. «Los maestros de primeras letras en la provincia de Madrid a través del Catastro de Ensenada», Historia y Memoria de la Educación, 3 (2016): 197-228. 
Abstract: This paper aims to offer a glimpse into the real situation of literacy teachers, and to a lesser extent, grammar teachers, in the province of Madrid in the 18th century, based on relevant information gathered from "Libros de Estados Generales» of "Catastro de Ensenada» (1749-1756). First, we analyze the distribution of literacy teachers in cities and villages in the Madrid area, their wages, the supplementary jobs they had apart from teaching, and how they were valued socially. We also compare their job to other types of professions in order to get a more accurate idea of their conditions and real situation in the mid-eighties. Similarly, we make a comparison of literacy teachers' and grammar teachers' socio-economic circumstances in the province of Madrid with that of teachers in other Spanish provinces where the "Catastro de Ensenada» was also conducted.

Keywords: Primary education. Teachers. "Catastro de Ensenada». School statistics. 18th century.

El siglo XVIII es un periodo de grandes cambios, cuyas bases se fundamentaban en la razón y la experiencia como medios para mejorar la educación, la cultura y la sociedad, entre otros. Para los ilustrados, de la educación dependía la felicidad de los hombres y esta felicidad era el principal objetivo que perseguía la naturaleza humana. ${ }^{1}$ Además, la educación era considerada como un elemento fundamental de socialización. Ahora bien, la realidad era otra. Las tasas de analfabetismo, a mediados de siglo, eran muy elevadas, la calidad del sistema era bastante baja y, sobre todo, la educación estaba bajo el control de la Iglesia. ${ }^{2}$

Por ello, los ilustrados se propusieron reformar el sistema educativo como paso previo al cambio de la sociedad y al desarrollo económico del país; tal y como reflejaron, entre otros, Floridablanca en la Instrucción reservada para la dirección de la Junta de Estado de 1787 o Jovellanos en su Memoria sobre la educación pública de $1808 .^{3}$ Sin embargo, el objetivo de este

\footnotetext{
${ }^{1}$ Véase, Agustín Escolano Benito, Educación y economía en la España ilustrada (Madrid: Ministerio de Educación y Ciencia, 1998).

${ }^{2}$ Sobre la alfabetización en dicho siglo, véase, entre otros, Jacques Soubeyroux, "Niveles de alfabetización en la España del siglo XVIII. Primeros resultados de una encuesta en curso", Revista de Historia Moderna, 5 (1985): 159-172; Jean-Paul Le Flem, «Instruction, lecture et écriture en Vieille-Castille et Extremadure aux XVIe-XVIIe siècles», en De l'alphabétisation aux circuits du livre en Espagne (París: Éditions du CNRS, 1987), 29-44; Antonio Viñao, «Alfabetización e ilustración diez años después (de las evidencias directas a las indirectas)», Bulletin Hispanique, 100 (2), (1988): 257-267.

${ }^{3}$ Floridablanca, «Instrucción reservada que la Junta de Estado, creada formalmente por mi Decreto de este día, 8 de julio de 1787, deberá observar en todos los puntos y ramos encargados de su conocimiento
} 
trabajo no es tanto un análisis de la situación educativa a tan gran escala, como analizar dicha situación en un ámbito muy concreto y puntual: la de los maestros de primeras letras en la provincia de Madrid, todavía inédita en trabajos precedentes, utilizando fundamentalmente la información que nos ha dejado el Catastro de Ensenada.

Dicha fuente, como es bien sabido, se realizó, principalmente, por motivos económicos y fiscales, con el objetivo de conocer la situación real del país, pues las rentas, impuestos y contribuciones eran muy desiguales entre las distintas clases sociales, siendo paradójicamente, y contrario a lo que cabría esperar, las clases más altas las que menos impuestos debían pagar y las clases más bajas las que más sufrían dicho sistema impositivo. De esta forma, el primer Marqués de la Ensenada, don Zenón de Somodevilla y Bengoechea, ${ }^{4}$ propuso a Felipe V primero, y a Fernando VI después, un proyecto consistente en catastrar las 22 provincias - a excepción de las Islas Canarias-que, por entonces, formaban el Reino de España, con el objetivo de poder realizar una reforma fiscal equitativa, en la que se valorase y recogiesen todos los datos relativos a las pertenencias que tenía cada habitante, para que de este modo tributara de acuerdo a sus posibilidades. ${ }^{5}$ El Marqués de la Ensenada pretendía erradicar los múltiples impuestos que antes existían y establecer una única contribución para cada individuo, que se ajustara a su nivel económico. Así, se realizó un intenso trabajo entre 1750 y 1757, intentándose recoger todos los datos relativos a los bienes inmuebles; sin embargo, y a pesar de sus fines fiscales iniciales, la extensa documentación que nos ha dejado el Catastro ha servido para estudios posteriores en disciplinas paralelas por la gran cantidad de datos demográficos, sociales, educativos, económicos, etc. aportados.

y examen», en Floridablanca, Escritos políticos. La Instrucción y el Memorial (Murcia: Academia Alfonso X el Sabio, 1982), 95-285 (edición y estudio preliminar de Joaquín Ruiz Abellán), y Gaspar Melchor de Jovellanos, «Memoria sobre la educación pública, o sea tratado teórico-práctico de enseñanza con aplicación a las escuelas y colegios de niños», en Obras completas. XIII. Escritos pedagógicos, $I^{\circ}$ (Oviedo: Ayuntamiento de Gijón, Instituto Feijoo de Estudios sobre el siglo XVIII y KRK ediciones, 2010), 435-532 (edición crítica, prólogo, estudio introductorio y notas de Olegario Negrín Fajardo).

${ }^{4}$ Sobre este personaje, véase, entre otros, Felipe Abad León, El marqués de la Ensenada (Rioja: Diputación de la Rioja, 1981) y José Luis Gómez Urdáñez, El proceso reformista del marqués de la Ensenada (Madrid: Milenio, 1996).

${ }_{5}^{5}$ Para una visión detallada de las bases del Catastro de Ensenada, véase: Concepción Camarero Bullón, «Averiguarlo todo de todos: El Catastro de Ensenada», Estudios Geográficos, 63 (2002): 493-532, y Antonio Domínguez Ortiz, «El Catastro de Ensenada en su circunstancia». CT: Catastro, 46 (2002): 7-16. 
Si bien es cierto que la documentación relativa a temas educativos era muy escasa e incompleta, el conocimiento de la mayoría de información de la que hoy día disponemos relacionada con ello es gracias a censos y padrones anteriores - cuyos fines eran otros- que han permitido un primer acercamiento al proceso escolarizador en la Corona de Castilla. ${ }^{6}$ Cabe destacar que no fue hasta 1790 cuando se intentó conocer cualitativamente la situación de la enseñanza primaria. ${ }^{7}$ Sin embargo, ello sólo quedó en un primer intento, pues no fue hasta la mitad del siglo XIX cuando las estadísticas escolares comenzaron a tener cabida bajo las directrices del Estado como herramientas de conocimiento de la situación real del sistema educativo del momento. ${ }^{8}$ Así, como se ha dicho anteriormente, aunque con fines distintos, el Catastro de Ensenada ha servido - entre otras muchas utilidades- para contribuir al conocimiento de la educación, aportando datos de gran interés en cuanto a maestros de primeras letras, objeto de estudio del presente trabajo. ${ }^{9}$

\section{ALGUNOS ASPECTOS GENERALES SOBRE LA ENSEÑANZA PRIMARIA EN LA ESPAÑA DEL SIGLO XVIII}

La educación ocupó un lugar central en el pensamiento de los ilustrados españoles, puesto que consideraban que a través de la misma se produciría la renovación cultural y el desarrollo económico, al mismo tiempo que afian-

\footnotetext{
6 Jean-Paul Le Flem, «Instruction, lecture et écriture en Vieille-Castille et Extremadure».

7 Jean-Louis Guereña, «La estadística escolar», en Historia de la educación en la España contemporánea. Diez, años de investigación, eds. Jean-Louis Guereña, Julio Ruiz Berrio y Alejandro Tiana (Madrid: Centro de Publicaciones del Ministerio de Educación y Ciencia, 1994), 51-76 (referencias en pp. 55-58), y JeanLouis Guereña y Antonio Viñao, Estadística escolar, proceso de escolarización y sistema educativo nacional en España, 1750-1850 (Barcelona: EUB, 1996), 24-27, y «Estadística escolar, proceso de escolarización y sistema educativo nacional en España (1750-1850)», Boletín de la Asociación de Demografía Histórica, XVII (II), (1999): 115-140.

${ }^{8}$ Al hilo de ello, cabe destacar que en 1829, en el primer manual de un autor español sobre estadística, las Lecciones de estadística de J. Herrera Dávila y de A. Alvear, en el punto LXXXVIII de la lección VI («Continuación de la Etnografía»), se incluían los «Establecimientos públicos para la educación moral y científica en diferentes parages, su suficiencia; cuales son las clases que más se frecuentan, ya quienes están encargadas; cursos de estudio en los colegios, en los liceos y en las academias; gobierno interior de estas casas de educación» (Herrera Dávila y Alvear, 1829: 45-46); recuperado de Jean-Louis Guereña y Antonio Viñao, «Estadística escolar, proceso de escolarización».

9 María del Carmen Labrador Herraiz, «Los maestros de primeras letras en el Catastro de Ensenada», en II Simposio sobre el padre Feijoo y su siglo (Oviedo: Universidad de Oviedo, 1983), 159-181 y La Escuela en el Catastro de Ensenada (Madrid: MEC, 1988).
} 
zarían su proyecto político. ${ }^{10}$ De este modo, se prestó una especial atención a la educación primaria, pues si en esa etapa se alcanzaban los principios de la gratuidad y obligatoriedad, podrían conseguir gran parte de sus ideas. ${ }^{11}$ La enseñanza de primeras letras estaba a cargo principalmente del clero regular o secular y, en menor medida, de maestros. Esta etapa se impartía en colegios de instituciones eclesiásticas o en escuelas municipales. Estas últimas, se concebían como preparación previa a la enseñanza de la Latinidad y en ellas únicamente podían impartir las lecciones maestros titulados por la Hermandad de San Casiano — constituida en 1642, por maestros de Madrid con el objetivo de mejorar la enseñanza-, o bien preceptores privados, fundamentalmente entre las clases más altas. ${ }^{12}$

Ahora bien, la situación de la educación en España era bastante deficiente, a pesar de los esfuerzos que se realizaron desde la referida creación en 1642 de la Hermandad de San Casiano. Los niveles de alfabetización eran muy bajos, al igual que los niveles de escolarización, ${ }^{13}$ la formación de

\footnotetext{
${ }^{10}$ Véanse, entre otros, AA. VV, Educación e ilustración en España. III Coloquio de Historia de la Educación (Barcelona: Departamento de Educación Comparada e Historia de la Educación, 1984); AA. VV., Simposio internacional sobre Educación e Ilustración. Dos siglos de reformas en la enseñanza (Madrid: Ministerio de Educación y Ciencia, 1988); AA. VV., «La educación en la Ilustración española», Revista de Educación (número extraordinario, 1988); y Clotilde Gutiérrez Gutiérrez, Enseñanza de primeras letras y latinidad en Cantabria (1700-1860), (Santander: Universidad de Cantabria, 2001).

${ }_{11}$ Sobre la enseñanza primaria en la España de la segunda mitad del siglo XVIII, véanse, entre otros, Jean-René Aymes, «Les ilustrados espagnols de la seconde moitié du XVIIIème siècle et l'enseignement élémentaire. Etude comparative», en Ecole et societé en Espagne et en Amérique Latine (XVIIIème-XXème siècles (Tours: CIREMIA, 1983): 9-48; Julio Ruiz Berrio, «La Educación del Pueblo Español en el proyecto de los ilustrados», Revista de Educación (número extraordinario, 1988): 163-193, y "Reformas de la enseñanza primaria en la España del Despotismo Ilustrado», en L'enseignement primaire en Espagne et en Amérique Latine du XVIIIème siècle à nos jours. Politiques éducatives et pratiques scolaires, (Tours: CIREMIA, 1986): 3-17; y Francisco Aguilar Piñal, La enseñanza primaria en Sevilla durante el siglo XVIII (Sevilla: Academia de Buenas Letras, 1974).

12 Miguel A. Pereyra, «La educación institucional: maestros de primeras letras. La Hermandad de San Casiano y las academias de maestros», en Historia de la Educación en España y América, coord., Buenaventura Delgado Criado (Morata: Fundación Santa María, vol. 2, 1993): 786-804, y Buenaventura Delgado Criado, «La formación del profesorado de primeras letras antes de la creación de las Escuelas Normales», en La investigación pedagógica y la formación de profesores (Madrid: Sociedad Española de Pedagogía-Instituto San José de Calasanz, 1980), 121-142.

${ }^{13}$ Además de las referencias bibliográficas indicadas en la nota n. ${ }^{\circ}$ 2, véase AA. VV., Del'alphabètisation aux circuits du livre en Espagne XVIe-XIXe siècles (Paris: CNRS, 1987); Antonio Viñao, "Alfabetización e Ilustración: difusión y usos de la cultura escrita», Revista de Educación (número extraordinario, 1988): 275-303; y Guereña y Viñao, Estadística escolar, proceso de escolarización y sistema educativo nacional en España (1750-1850), 39-45.
} 
los profesores asimismo muy deficiente, ${ }^{14} \mathrm{y}$ el control del Estado sobre la misma bastante escasa, pues no se debe olvidar que la Iglesia era quién realmente monopolizaba la educación en España. ${ }^{15}$ En muchos casos el simple hecho de tener nociones básicas de cálculo, escritura y lectura, así como de doctrina cristiana eran aspectos más que suficientes para enseñar primeras letras. Por ello, no nos puede sorprender que en muchos lugares el sacristán fuese el encargado de enseñar a los jóvenes de los lugares y villas de Castilla. Esta escasa preparación tenía una clara repercusión tanto en la concepción social del oficio como en la formación recibida, lo que lastraba el desarrollo económico. Como bien ha señalado Gutiérrez Barba,

bien por razones económicas, bien por la necesidad de realización de labores agrarias, o bien por la desidia de los padres, la asistencia a clases es muy escasa incluso en las primeras edades de escolarización. En las últimas edades el absentismo escolar es generalizado. ${ }^{16}$

Para solucionar este importante problema se comenzó a exigir a los aspirantes al magisterio primario la superación de un proceso selectivo que probaba los conocimientos que se tenían en lectura, escritura — de mayor peso sobre los demás-, conteo y doctrina cristiana. También, debían presentar un informe sobre sus costumbres y limpieza de sangre al corregidor o alcalde - principales cargos municipales-, quiénes más tarde darían cuenta a la justicia sobre la veracidad de dicho informe. Una vez superadas ambas pruebas, se les expedía el título correspondiente y los corregidores o alcaldes serían los encargados de supervisar que los maestros titulados enseñaran primeras letras y formaran en buenas costumbres a sus discípu-

\footnotetext{
14 Véase Antonio Peñafiel Ramón, «En torno a la situación de los maestros de primeras letras en Murcia a mediados del siglo XVIII", Monteagudo. Revista de literatura española, hispanoamericana y teoría de la literatura, 83 (1983): 23-30; Julio Ruiz Berrio, «La crisis del profesor español en la Ilustración», en Simposio Internacional sobre Educación e Ilustración, 223-243; Alejandro Ávila Fernández, «La formación de maestros de primeras letras en España y en Sevilla durante los siglos XVII y XVIII», Cuestiones pedagógicas. Revista de Ciencias de la Educación 3 (1986): 23-40; y Jean-Pierre Amalric et al. "Un reseau d'enseignement elementaire au XVIIIe siècle dans les campagnes de Burgos et Santander», en AA. VV., Del'alphabètisation aux circuits du livre en Espagne, 9-27.

${ }_{15} \mathrm{Al}$ respecto, Jesús Llopis y María Victoria Carrasco, Ilustración y educación en la España del siglo XVIII (Valencia: Publicaciones de la Escuela Universitaria del Profesorado de EGB, 1983), passim, y Olegario Negrín Fajardo, Educación popular en la España de la segunda mitad del siglo XVIII (Madrid: UNED, 1987), passim.

16 Alfonso Gutiérrez Barba, "Situación de la enseñanza de primeras letras en la comarca de Tentudia entre mediados del siglo XVIII y mediados del XIX», en Actas del I Congreso de la Memoria Colectiva de Tentudia (Badajoz. Centro de Desarrollo Comarcal de Tentudia, 2001): 451.
} 
los. Por desgracia no muchos de los maestros que ejercían habían pasado estas pruebas, sobre todo en el ámbito rural donde la «enseñanza primaria estaba a cargo de maestros muy deficientes»; la situación era muy distinta en entornos urbanos, donde por el contrario «poco tendría que ver la preparación y la dedicación profesional de los maestros urbanos, que eran verdaderos especialistas en la enseñanza, con la de los residentes en los pequeños pueblos». ${ }^{17}$

Además, para aumentar el control, en 1780 desapareció la Hermandad de San Casiano y, en su lugar, se creó el Colegio Académico del Noble Arte de Primeras Letras, que se constituyó para perfeccionar la formación obtenida tras superar los estudios de primeras letras en las escuelas. La mayoría de maestros que salieron de este Colegio dirigieron las escuelas públicas de la Corte e impartían enseñanza pública sobre gramática o aritmética. De igual forma, se creó la Escuela de la Real Comitiva, pero ésta únicamente abría sus puertas a hijos de criados o trabajadores de la Corte.

Junto a esta deficiente formación de los maestros, otro problema tenía que ver con la retribución de su trabajo, como veremos más adelante en el caso concreto de la provincia de Madrid. En la mayoría de las ocasiones los salarios no alcanzaban para poder vivir; por lo que, a menudo, recurrían al ejercicio de alguna otra profesión para mejorar sus emolumentos, concretamente a la de sacristán, escribano, tabernero o notario apostólico, y en muchos casos, la maltrecha hacienda municipal impedía el pago puntual del mismo —en ocasiones, incluso de meses y años-.$^{18}$ Esta situación era aún peor en los maestros rurales que en los de las ciudades ${ }^{19} \mathrm{y}$, sobre todo, dentro del muy reducido grupo de maestras. Éstas, a menudo, no sabían ni leer ni escribir, únicamente se dedicaban a la enseñanza de la doctrina cristiana, que se sabían de memoria. ${ }^{20}$

\footnotetext{
${ }^{17}$ Francisco Javier Laspalas Pérez, «La condición social y profesional de los maestros de primeras letras en Navarra durante la segunda mitad del siglo XVIII», Príncipe de Viana, 254 (2011): 493.

${ }^{18} \mathrm{Al}$ respecto, de manera general, Carmen García García, La crisis de las haciendas locales: de la reforma administrativa a la reforma fiscal (1743-1845) (Salamanca: Junta de Castilla y León, 1996).

${ }_{19} \mathrm{Al}$ respecto, Anastasio Martínez Navarro, El estado de la enseñanza en el Arzobispado de Toledo bajo el pontificado del Cardenal de Borbón (1800-1824) (Madrid: Universidad Complutense, 1981), y Labrador Herraiz, La Escuela en el Catastro de Ensenada.

${ }^{20}$ Para conocer más sobre la situación de la mujer en este periodo, véase: Margarita Ortega López, «La educación de la mujer en la ilustración española», en Simposium internacional sobre Educación e Ilustración, 193-223; María Begoña Villar García, «Las oportunidades de educación y el empleo laboral de las mujeres malagueñas en la Edad Moderna», Baética: Estudios de arte, geografía e historia, 25 (2003): 649-
} 
Resultado quizás de estas dos situaciones: deficiente formación y escasa retribución, era el hecho de que la figura del maestro estuviera muy poco considerada en la sociedad. Como ha señalado Laspalas Pérez,

que el maestro faltase a la escuela con cierta frecuencia era algo que se consideraba relativamente normal, puesto que los contratos de conducción y las ordenanzas escolares de algunos pueblos le autorizaban expresamente a ausentarse, ${ }^{21}$

por lo que no puede sorprendernos que los jornaleros tuviesen mayor reconocimiento y por lo tanto mejor retribución:

se estima que un jornalero ganaba en Navarra durante el siglo XVIII, sumados sus ingresos monetarios y en especie, entre 400 y 450 reales. Mientras que un maestro ovetense estima necesario para mantener a su familia 17 reales de vellón y 6 maravedíes diarios. ${ }^{22}$

Esta baja retribución, junto con su escasa cualificación y la mala consideración social que solían tener, hacía que los maestros, como señaló Domínguez Ortiz, fueran «una figura desdibujada». ${ }^{23}$

Además, la educación de primeras letras era diferenciada por sexos: niños y niñas. En este sentido, podemos señalar, la creación en 1768 de las denominadas Casas para la Educación de los niños, donde las materias que se debían enseñar eran las primeras letras, gramática, retórica y aritmética, entre otras, y las Casas para la Educación de las niñas, con unos contenidos que se basaban en las obligaciones propias de las mujeres en el ámbito doméstico y sobre la moral y la virtud. Estas escuelas se costeaban con los impuestos municipales. ${ }^{24}$ Con todo, a pesar de estos pequeños avances, y como

\footnotetext{
670; María Victoria López-Cordón Cortezo, Condición femenina y razón ilustrada. Josefa Amar y Borbón, (Zaragoza: Prensas Universitarias de Zaragoza, 2005), y Fernando Fernández Chacón «La enseñanza de las primeras letras en el tránsito del Antiguo Régimen al Sistema Liberal (1768-1823), Maestros-as, escuelas y educación de las niñas en Linares y Jaén», Boletín del Instituto de Estudios Giennenses, 201 (2010): 235-262.

${ }^{21}$ Laspalas Pérez, «La condición social y profesional de los maestros», 492.

${ }^{22}$ Laspalas Pérez, «La condición social y profesional de los maestros», 485.

23 Antonio Domínguez Ortiz, La sociedad española en el siglo XVIII (Barcelona: Ariel, 1986), 173.

${ }^{24}$ Puede verse, entre otros, Carmen Sarasúa García, «El acceso de niñas y niños a los recursos educativos en la España rural del siglo XIX», en El nivel de vida en la España rural del siglo XIX, ed. José Miguel Martínez Carrión (Alicante: Universidad de Alicante, 2002): 549-612.
} 
ya hemos apuntado, el clero, tanto el regular como el secular, mantuvo un estrecho control sobre esta etapa educativa, sobre todo por la incapacidad del Estado - y en su defecto de los municipios-, de poder ofrecer una educación universal y gratuita.

\section{LOS MAESTROS DE PRIMERAS LETRAS EN LA PROVINCIA DE MADRID SEGÚN EL CATASTRO DE ENSENADA}

El presente trabajo pretende ofrecer una aproximación a la realidad de la situación de los maestros de primeras letras en la antigua Provincia de Madrid a través de la información que nos proporcionan los Libros Generales del Catastro de Ensenada —realizado entre 1749 y 1756-, concretamente, a través de las respuestas obtenidas a partir de las preguntas $25,{ }^{25} 26,{ }^{26}$ $32,{ }^{27}$ y $33,{ }^{28}$ ésta última, de gran utilidad para los municipios de Belmonte del Tajo, Borox, Illana y Moraleja la de Enmedio, entre otros.

Las respuestas generales que el Catastro de Ensenada nos ha dejado de los 99 pueblos que componían la antigua provincia de Madrid $^{29}$ han sido la base principal para el desarrollo del presente trabajo. La antigua provincia de Madrid puede ser delimitada en cinco grandes territorios: el partido de la Alcarria, las tierras del suroeste, tierras al sur y al norte, villas en el entorno de Madrid y las aldeas de la misma. ${ }^{30}$

\footnotetext{
25 «Qué gastos debe satisfacer el Común como salario de Justicia, y Regidores, fiestas de Corpus u otras: Empedrado, Fuentes, Sirvientes, etc., de que se deverá pedir relación authéntica».

26 «Qué cargos de Justicia tiene el Común, como censos, que responda, u otros, su importe, por qué motivo, y a quién, de que se deverá pedir puntual noticia».

27 «Si en el pueblo hay algún Tendero de Paños, Ropas de Oro, Plata y Seda, Lienzos, Especería u otras Mercadurías, Médicos, Cirujanos, Boticarios, Escrivanos, Arrieros, etc. y qué ganancia se regula puede tener cada uno al año».

28 «Qué ocupaciones de Artes mecánicas hay en el Pueblo con distinción, como Albañiles, Canteros, Albéytares, Herreros, Sogueros, Zapateros, Sastres, Perayres, Tejedores, Sombrereros, Manguiteros y Guanteros, etc. explicando en cada oficio de los que huviere el número que haya de Maestros, Oficiales, y Aprendices; y qué utilidad le puede resultar, trabajando meramente de su Oficio, al día cada uno».

${ }^{29}$ Los pueblos que componían la provincia del Madrid durante los años centrales del Catastro de Ensenada, en realidad, eran 100 pero la operación catastral de Villafranca del Castillo se realizó una vez ya enviadas las Respuestas generales de todos los pueblos a la Real Junta de Única Contribución, por lo que no se dispone de la documentación referida a dicho pueblo. Concepción Camarero Bullón, Madrid y su provincia en el Catastro de Ensenada. II. Los pueblos de Madrid (1750-1759) (Madrid: Ediciones del Umbral, 2005), 7.

${ }^{30}$ La división realizada de los pueblos de la provincia de Madrid, para una mayor clarificación en el presente trabajo, es la seguida por Camarero Bullón, Madrid y su provincia en el Catastro de Ensenada. II.
} 
Respecto al partido de la Alcarria, estaba formado por 27 villas y seis despoblados. ${ }^{31}$ Dicho partido era atravesado por el río Tajo en el este, quedando dividido en dos partes: a la derecha del Tajo se localizaban 22 villas mientras que a la izquierda quedaban cinco. Al sur limitaba con la provincia de Cuenca y al oeste y al norte con el Tajuña. De las 27 villas y seis despoblados cabe destacar que 24 de ellos eran de señorío, seis de realengo y solo tres tenían el régimen dividido. En este partido se localizaban un total de 22 maestros (los lugares, villas y aldeas donde se encontraban estos maestros, así como los sucesivos, se detallan en la tabla 3).

En cuanto a las tierras del suroeste, tenían diez villas que limitaban al este, al sur y al oeste con la provincia de Toledo y al norte con la de Segovia. Todas estas villas: Val de Santo Domingo, Carmena, Maqueda, Quismondo, Santa Cruz de Retamar, Casarrubios del Monte, Ventas de Retamosa, Valmojado, Villamanta y Álamo, eran de señorío y en cinco de ellas había maestro. En relación a las tierras al sur y al norte, hay que decir que eran cuatro villas: Belmonte del Tajo, Pedrezuela, San Agustín de Guadalix y Borox, las tres primeras de señorío y la última de realengo. Belmonte del Tajo y Borox se encontraban al sur y al oeste y limitaban con la provincia de Toledo; mientras que Pedrezuela y San Agustín de Guadalix estaban en el norte y limitaban con Guadalajara. Solamente San Agustín de Guadalix presentaba vinculación geográfica con la provincia y tres de estas villas tenían maestro.

Respecto a las villas en el entorno de Madrid, ${ }^{32}$ limitaban al este con Toledo y el río Jarama, dejando en la margen derecha los pueblos de Velilla de San Antonio y Mejorada del Campo; al sur, también, limitaba con Toledo, al oeste con el río Guadarrama, que dejaba en su margen izquierda cinco pueblos: Quijorna, Villafranca del Castillo, Brunete, Sacedón de los Canales y Villaviciosa de Odón, y al norte con Guadalajara. Casi podría decirse que era el territorio más extenso, aunque poseía el mismo número de pueblos

\footnotetext{
${ }^{31}$ Las villas que componían el Partido de la Alcarria eran: Pastrana, Sayatón, Yebra, Escariche, Escopete, Hontoba, Hueva, Valdeconcha, Almoguera, Mazuecos, Driebes, Brea del Tajo, Fuentenovilla, Pozo de Almoguera, Albares, Fuentelencina, Alhóndiga, Auñón, Moratilla, Peñalver, Berninches, Alocén, Almonacid de Zorita, Buendía, Albalate, Illana y Zorita de los Canes. Mientras que los despoblados eran: Anguix, El Común de las Once Villas, La Pangía, Sever, Valdecanal y Valles y Cabanillas.

${ }^{32}$ Las villas del entorno de Madrid eran Barajas, Rejas, Coslada, Mejorada, Velilla de San Antonio, Rivas, Vaciamadrid, Perales del Río, Torrejón de Velasco, Parla, Cubas, Griñón, Serranillos, Moraleja la de Enmedio, Moraleja la Mayor, Arroyomolinos, Villa de Odón o Villaviciosa, Sacedón de los Canales, Brunete, Quijorna, Boadilla del Monte, Romanillos, Chamartín, Hortaleza, Canillas, Canillejas, Alameda, Leganés, Polvoranca, Húmera, Pozuelo, Aravaca y el Real Sitio de Gózquez.
} 
que el partido de la Alcarria: 33, conformado por 32 villas y el Real Sitio de Gózquez. ${ }^{33}$ Doce de estas villas tenían maestro.

Por último, en cuanto al conjunto de las aldeas de Madrid, hay que señalar que lo componían 18 aldeas $^{34}$ y la villa del campo de Madrid; todas ellas de realengo, a excepción de Alcobendas, cuyo régimen era compartido. Estas aldeas se localizaban bordeando la ciudad de Madrid y limitaban con las villas tratadas en el párrafo anterior. En ellas se localizan trece maestros distribuidos en diez pueblos, pues algunos de ellos tenían dos.

De este modo, de un total de 99 pueblos, tan solo en 53 - poco más de la mitad-, había maestros. En la villa de Vallecas había dos y en las de Villaverde y Alcorcón un maestro y una maestra (véase el mapa de la localización geográfica de los pueblos de la antigua provincia de Madrid). En contraste, en los datos ofrecidos por Labrador Herráiz en la provincia de Guadalajara, solamente se hallaba una maestra en la villa de Hijes con un salario de 300 reales. Sin embargo, resulta sorprendente que en la provincia de Salamanca se localizasen seis, con retribuciones entre 400 reales la más alta y 72 la más baja, aunque también hay que decir que Salamanca triplicaba en pueblos a Guadalajara, que a su vez triplicaba a Madrid. ${ }^{35}$

Si analizamos con detenimiento los salarios de los maestros en la Provincia de Madrid, se aprecia que el sueldo más alto se daba en la aldea de Fuenlabrada donde percibía 3.000 reales de vellón, ${ }^{36}$ San Agustín de Guadalix con 2.200 reales o Alcorcón con 2.031, mientras que los más bajos se daban en Borox con 150 reales, Escopete donde apenas percibía 30 reales o Peñalver, donde no se le daba nada. El salario medio oscilaba entre 600-700 reales. Sin embargo, no existía un correlato entre el nivel de rentas de la lo-

\footnotetext{
${ }^{33}$ Sobre este lugar, véase el reciente estudio de Concepción Camarero Bullón, y Jesús Campos Delgado, «El Real Sitio de Gózquez y el mantenimiento de El Escorial», en Hacer Historia desde Simancas. Homenaje a José Luis Rodríguez de Diego, ed. Alberto Marcos Martín (Valladolid: Junta de Castilla y León, 2011), 187-215.

${ }^{34}$ Las aldeas que componían Madrid eran: Fuente el Fresno, San Sebastián de los Reyes, Alcobendas, Fuencarral, Ambroz, Vicálvaro, Vallecas, Villaverde, Getafe, Casarrubuelos, Torrejón de la Calzada, Humanejos, Fuenlabrada, Alcorcón, Carabanchel de Arriba y Carabanchel de Abajo, Majadahonda, Rozas y la villa del Campo de Madrid.

${ }^{35}$ Labrador Herraiz, La Escuela en el catastro de Ensenada.

36 El dato de Fuenlabrada no es muy fiable debido a que «Sebastián operó íntegramente Fuenlabrada en 45 días, siendo así que tenía una población de 450 vecinos y que en otras provincias se había empleado el cuádruple de tiempo para operar poblaciones similares». Concepción Camarero Bullón, Madrid y su provincia en el Catastro de Ensenada. II., 434. De hecho, el interrogatorio fue repetido hasta en tres ocasiones.
} 
calidad y el salario de los maestros, ya que de los tres pueblos en los que se aprecia el sueldo más alto para el maestro de primeras letras (Fuenlabrada, San Agustín de Guadalix o Alcorcón) ninguno de ellos presenta altos niveles de ingresos, pues oscilaban entre los 33.000-40.000 reales, habiendo pueblos con ingresos muy superiores como era el caso de los Carabancheles, con ingresos alrededor de los 92.000 reales que, a pesar de ello, compartían maestro, o el caso de Boadilla del Monte con ingresos alrededor de 75.000 reales y con el sueldo de maestro de 500 reales. Aunque, no hay que dejar de señalar el caso de Vallecas y de Leganés, que teniendo ingresos bien altos, poseían dos maestros y un maestro y un preceptor, respectivamente.

De hecho, de los pueblos escogidos (Vallecas, Vicálvaro, Leganés, Fuencarral, los Carabancheles, Boadilla del Monte y Aravaca) con mayores niveles de ingresos — de 75.000 reales en adelante-, cuatro de ellos (Vallecas, Vicálvaro, Fuencarral y Los Carabancheles) coinciden en que eran aldeas de régimen realengo, cuyas retribuciones al maestro son las más altas: de 900 reales en adelante. Aunque también podríamos incluir a Leganés que no era aldea, sino villa del entorno inmediato a Madrid cuyos ingresos eran los más altos de todos los pueblos que componían la provincia, y la retribución al maestro y preceptor de su villa no estaba mal: 1.800 y 1.900 reales, respectivamente. Por el contrario, aquellos pueblos en los que el salario por el oficio de maestro era realmente ínfimo, advertimos que sus niveles de renta no eran especialmente elevados; así, en el caso de Borox, presentaba unos ingresos de 25.686 reales y unos gastos de 14.511 reales; además, Escopete decía no tener ingresos, pero sí gastos y Peñalver tenía unos gastos superiores al nivel de ingresos. En esta misma línea, podría destacarse el caso de la villa de Béjar (Salamanca) cuyo maestro, con lo que le retribuía la villa y lo que le daban los niños, sumaba alrededor de 120 reales.

Asimismo, si seguimos observando los niveles de ingresos y gastos de los diferentes pueblos de la provincia, sorprende que de entre los pueblos sin maestro, sólo hubiera cuatro cuyos gastos fueran superiores al nivel de ingresos. Sin embargo, en la misma circunstancia pero con maestros, había doce pueblos. Cabría esperar que, debido a la poca importancia otorgada a la figura del maestro, se prescindiera de la misma, pues sería un gasto menos aunque en ocasiones dicho gasto no fuera significativo. Además, once de estos doce pueblos se localizan en la Alcarria, de los cuales ocho de ellos tienen maestro. No obstante, y como podría suponerse, el salario medio de un maestro en el partido de la Alcarria (750 reales) distaba mucho del que 
percibían en las aldeas de Madrid (1.300 reales), pues dicho territorio no presentaba ningún pueblo cuyos gastos fueran superiores a los ingresos, y en general, los ingresos eran bastante elevados (véanse las tablas 1 y 2 : rentas de pueblos de la provincia con maestros de primeras letras y rentas de pueblos de la provincia sin maestros de primeras letras, respectivamente).

Por otro lado, del total de municipios, en catorce de ellos los maestros percibían emolumentos que oscilaban entre los 600 y los 1.000 reales; en once, los ingresos eran inferiores a los 300, aunque en este caso es preciso indicar que en siete de estos lugares los maestros simultaneaban este oficio; en nueve (Albalate, Alcobendas, Aravaca, Brunete, Buendía, Casarrubios del Monte, Escariche, Fuentelencina y Torrejón de Velasco), entre 1.000 y 1.500; en siete, teniendo en cuenta que Villaverde tenía dos maestros (Boadilla del Monte, Carmena, Griñón, Mazuecos, Moratilla, Rozas y Villaverde), variaban entre los 300 y los 600; y en cuatro, contando con que Vallecas tenía dos maestros (Barajas, Leganés, Pastrana y Vallecas), entre 1.500 y 2.000. Tan solo en Alcorcón, los Carabancheles, Fuenlabrada y San Agustín de Guadalix, los maestros percibían salarios superiores a los 2.000 reales de vellón. En los casos de Alocén, Berninches, Moraleja la de Enmedio o San Sebastián de los Reyes, los salarios de maestros de primeras letras no se pueden encuadrar en un rango exacto, ya que las respuestas generales no ofrecen en detalle la cantidad percibida por tal oficio, sino que muestra la retribución total por todos los oficios que ejercía el maestro (véanse tablas 3 y 4: retribuciones aproximadas del oficio de maestro de primeras letras y retribuciones de los oficios simultaneados de los maestro de primeras letras, respectivamente).

Del mismo modo, se producía una importante diferencia salarial entre maestros y maestras en el caso de los dos lugares donde las había: Villaverde y Alcorcón. En ambos lugares los emolumentos de las maestras eran muy parecidos: 220 y 200, respectivamente, ${ }^{37}$ frente a los 650 y 2.031 reales de vellón que percibían sus maestros. Además, en el caso de las maestras las cifras son estimativas ya que su salario era pagado por las niñas a las que daban clase.

\footnotetext{
37 Conviene destacar un dato interesante: «más problemático resulta averiguar [...] cuáles eran los atractivos de que un oficio tan mal pagado podía tener. Lo más probable es que para algunas mujeres casadas el oficio de maestra fuese una interesante fuente de ingresos complementarios que sumar a los que su marido obtenía, aunque entre las maestras no faltaban tampoco las viudas y solteras» (Laspalas Pérez, «La condición social y profesional de los maestros», 487).
} 
Las condiciones donde se impartían las clases tampoco eran las mejores. En muchos casos las propias corporaciones locales cedían estos lugares. Suárez Goldán, para el ámbito de Galicia, afirma que «una enseñanza tan precaria tenía lugar, además, en locales que no reunían las mínimas condiciones infraestructurales ni estaban dotados de material suficiente». ${ }^{38}$

Al tener salarios tan bajos, ${ }^{39}$ en muchos pueblos los maestros compaginaban este oficio con otros. En Madrid, al contrario de lo que ocurría en otros lugares, los maestros que no simultaneaban el oficio, doblaban en número a los que sí lo hacían. Así, 38 de ellos —incluidas las dos mujeres- no ejercían otro oficio, mientras que tan solo 16 lo hacían. Siete lo simultaneaban con otro oficio: este era el caso de Albalate, Almoguera, Almonacid de Zorita, Hueva, Moraleja de Enmedio y San Sebastián de los Reyes; seis con dos oficios en Alocén, Belmonte del Tajo, Berninches, Escopete, Hontoba y Yebra; y los restantes, con tres, eran Alhóndiga, Auñón y Peñalver. ${ }^{40}$ Los oficios más frecuentes para simultanear con el de maestro eran el de sacristán (10 de los 16), seguido del de notario apostólico (ocho) y, en menor medida, encargados del gobierno del reloj (seis), escribanos (tres) y zapatero (uno). En este sentido, la provincia de Madrid se comportaba de manera similar a, por ejemplo, Guadalajara y Palencia, aunque en esta última el segundo oficio en importancia, cuando se compaginaba, era el de agrimensor.

${ }^{38}$ Fernando Suárez Goldán, «Niveles de enseñanza y estudiantes en la Galicia Central del Antiguo al Nuevo Régimen», Obradoiro de Historia Moderna, 16 (2007): 317. La situación no parece que mejorase con los años; por ejemplo en Extremadura, algunas actas de la Junta de Escuelas (1845), donde las condiciones en las que se impartía enseñanza continuaban de forma muy parecida: «a la misma corporación se les hará presente la necesidad de poner cristales en las ventanas de los establecimientos para abrigo de los niños, puesto la estación rigurosa de Invierno en que nos hallamos, como así mismo el de dar más luz a la Escuela [...] (1845)», o «necesidad de que se abra una ventana que dé más luz y ventilación del local donde se da la enseñanza, en atención a que se observa no tiene suficiente [...] (1850)». Expediente 1, servicios, legajo 474, Archivo Municipal Mérida [AMM en adelante].

${ }^{39}$ A hilo de ello, y por datos de otras provincias, puesto que las Respuestas generales de Madrid apenas lo aportan dentro del salario de maestro, el Común les incluía en el mismo la casa en la que alojarse.

${ }^{40}$ De los 120 maestros que se localizan en la provincia de Guadalajara (según los datos extraídos de Labrador Herraiz, La Escuela en el Catastro de Ensenada) poco más de un cuarto solamente se dedicaban a la enseñanza de primeras letras. Los tres cuartos restantes combinaban el oficio, al menos, con otro más; hecho que ocurre a la inversa en la provincia de Madrid, como podemos ver en el presente trabajo, y en la provincia de Palencia que, según María del Carmen Labrador Herraiz y Margarita Nieto Bedoya, "La escuela en el Antiguo Régimen: los maestros de primeras letras en la provincia de Palencia», Actas del Primer Congreso de Historia de Palencia (Palencia: Diputación Provincial de Palencia, 1987), vol. 3, 504, de los datos recogidos de 54 pueblos, «son 51 los que enseñan y 12 los que trabajan, además, en otras tareas». 
Cuando se simultaneaban diferentes oficios el resultado, grosso modo, permitía una equiparación a otras profesiones liberales. Así, el maestro de Moraleja de Enmedio, que tenía el mayor salario de entre los que simultaneaban oficios, percibía 3.000 reales por maestro y zapatero. Aunque no siempre el hecho de simultanear oficios les hacía conseguir un salario mayor, como eran los casos, por ejemplo de Hueva, donde el maestro era también sacristán, y ganaba algo más del doble por sacristán que por maestro —unos 804 reales-; de Berninches, donde el maestro recibía 562 reales por los oficios de maestro, sacristán y relojero, e incluso de Escopete, cuyo maestro recibía 205,23 reales por sacristán, 20 por notario y 30 por maestro, lo que suponía un total de 255,23 reales (véase la tabla 5: profesiones simultaneadas con el oficio de maestro de primeras letras).

Por otro lado, si comparamos estos salarios con los de otras profesiones liberales, comprobamos que las retribuciones de los maestros eran bastante bajas. Así, por ejemplo, en el caso de los médicos nos encontramos con que en la aldea de Getafe —el lugar donde percibía una retribución más altarecibían 17.000 reales (13.500 reales de situado y 3.500 de emolumentos contingentes), mientras que en las villas de Griñón o Chamartín, —los lugares con salarios más bajos- percibían 700 reales de vellón, aunque no era lo normal, pues por el oficio de médico solían ganar de 1.100 reales de vellón en adelante. Sin embargo, es llamativo lo que ocurría en Moraleja la de Enmedio, pues si se comparan los salarios del médico y del maestro, podremos observar que este último percibía, sorprendentemente, un salario mayor al del médico: 3.000 reales frente a los 4,5 reales diarios del médico. ${ }^{41}$

De cualquier forma, la comparación tampoco es mucho mejor si lo hacemos con el oficio de sacristán, cuyo salario, de media, oscilaba en torno a los 1.500 reales. De acuerdo a la tabla 6 sobre los salarios de profesiones liberales en la provincia de Madrid, - en ella solamente se reflejan los dos pueblos que se han considerado más representativos de cada uno de los territorios en los que se ha dividido la provincia de Madrid, más arriba mencionados, considerando que tuvieran al menos entre cuatro y cinco artes liberales, sin contar la de maestro-, sólo en Pastrana, Barajas y Leganés el salario de los maestros superaba al de los cirujanos, boticarios o sacristanes. En Pastrana la diferencia, por ejemplo, con el sacristán era significativa, unos 1.300 reales, mientras que en Barajas y Leganés apenas suponía 500 y 300, respectivamente.

\footnotetext{
${ }^{41}$ El salario de médico en Madrid solía oscilar entre los 14-15 reales de vellón al día, salvo excepciones.
} 
Por otro lado, las Respuestas generales del Catastro en la provincia de Madrid no arrojan mucha luz en lo que se refiere a la procedencia de los salarios -municipal, fundacional o vecinal-, excepto casos como Alcobendas o Leganés, en los que se explicitaba que los salarios del maestro eran pagados por el concejo. Si bien, tomando como válida la referencia «al no indicar procedencia distinta, los municipios aportan el total o una buena parte de los salarios de los maestros», ${ }^{42}$ podemos afirmar que la mayoría de los mismos procede de las arcas municipales, aunque también hay casos de pago por parte de los vecinos. Cabe destacar, como ejemplo, el caso de Parla, cuyo maestro era retribuido por el Común con 400 reales y por los niños que asistían a la escuela con otros 400, o el de Mazuecos en donde el Común pagaba 500 reales y los vecinos, sin especificar cuantía, también le retribuían.

La gran mayoría del pago de estos salarios se hacía en moneda de vellón o en ducados. En muy pocos casos, como en Pedrezuela o Velilla de San Antonio, se retribuían las artes liberales en especies, concretamente, en fanegas de trigo. Ahora bien, esta práctica era más común en otras provincias como Palencia o Extremadura, especialmente rurales, ${ }^{43}$ e incluso en Valladolid dónde «es muy frecuente que todos estos oficios - guarda de bosques, maestro, sacristán, fiel de fechos...- que hemos ido enumerando sean pagados en especie, bien mediante determinada cantidad de cereales o con la cesión de una casa propiedad de la pedanía». ${ }^{44}$

Asimismo, en las Respuestas generales también encontramos otro oficio vinculado con la enseñanza, como era el de preceptor de gramática, ${ }^{45}$ que tampoco tenía mejor fortuna. Si resultaba escaso el número de maestros en la provincia madrileña — 53 maestros en 99 pueblos—, más lo era todavía el de los preceptores de gramática: tan solo había tres en Almoguera, Illana y

\footnotetext{
${ }^{42}$ Labrador Herraiz, y Nieto Bedoya, «La escuela en el Antiguo Régimen», 502.

${ }^{43}$ Véase al respecto, Margarita Nieto Bedoya, La escuela en el medio rural Provincia de Palencia a mediados del siglo XVIII (1752) (Madrid: Universidad Complutense, 1988); Labrador Herraiz, y Nieto Bedoya, "La escuela en el Antiguo Régimen»; y Juan Carlos Vázquez Calvo, Historia de la educación pública de Extremadura en el Antiguo Régimen (siglos XVI, XVII y XVIII) (Mérida: Junta de Extremadura. Secretaría General de Educación, 2004).

${ }^{44}$ García García, La crisis de las haciendas locales, 123.

${ }^{45}$ Sobre este oficio, puede verse, León Esteban Mateo, «Un manuscrito inédito en torno a las constituciones para el preceptor de gramática y maestros de primeras letras en la ciudad de Lorca en 1800", Historia de la Educación. Revista Interuniversitaria, 16 (1997): 411-427, y Amparo García Cuadrado, «Un preceptor de Gramática y su biblioteca en 1752», Boletín de la ANABAD, 57 (2007): 107-128.
} 
Leganés. ${ }^{46}$ Sólo uno de ellos, el de Leganés, se dedicaba únicamente a dicho oficio, mientras que tanto en Almoguera como en Illana lo simultaneaban con el de sacristán, e incluso con el de notario apostólico, en el caso de Illana. Los preceptores de gramática se localizaban, generalmente en las villas más grandes, aunque en este caso, las tres citadas no eran de las más habitadas de la provincia. Los salarios que percibían no eran especialmente elevados. El que más recibía era el de Almoguera — 2.519 reales-, si bien, simultaneaba su oficio con el de sacristán, el de Illana recibía 1.500 —aunque también lo simultaneaba- y el de Leganés ganaba 1.900 reales. Es decir, la mayoría de los preceptores debían simultanear su oficio con otro; ahora bien, cuando esto se hacía sus retribuciones finales siempre eran mucho más altas que las de los maestros. Así, por ejemplo, mientras que en Illana por los oficios de preceptor, sacristán y notario se ganaban 1.500 reales, en Alocén, el maestro, que también era sacristán y notario apostólico, percibía 991 reales, y en Escopete el maestro, que tenía los mismos cargos que en Alocén, percibía 255,23 reales.

\section{CONCLUSIONES}

A modo de conclusión podemos señalar que a pesar de que los ilustrados pretendían hacer del siglo XVIII un siglo de grandes cambios; no se pudo por menos dejar atrás varios de sus objetivos iniciales, pues la sociedad del momento no estaba preparada para tan importantes reformas, sin contar con la difícil situación de la hacienda regia. En el ámbito concreto de la educación, a pesar de haber tenido algunos éxitos en el ámbito universitario, en lo que respecta a la enseñanza de las primeras letras la situación no cambió mucho con respecto a tiempos anteriores. Los maestros de primeras letras y los preceptores de gramática seguían estando, en general, deficientemente formados y su reconocimiento social y económico muy por debajo de otros grupos profesionales. Dicha situación no fue mucho mejor en los años posteriores, pues a pesar de los intentos de cambio de años atrás, la situación de la educación estaba estancada en el desasosiego y la pasividad de la sociedad, aunque no es menos cierto que se reconocía, reiteradamente, la importancia de la educación:

${ }^{46}$ En el libro de María del Carmen Labrador Herraiz, La Escuela en el Catastro de Ensenada, se advierte que de un total de 120 municipios analizados, había 13 preceptores de Gramática, dos de Latinidad y Retórica y uno de Humanidades. En el caso de los pueblos de la Provincia de Madrid, no hemos encontrado preceptores de Latinidad y Retórica y de Humanidades. 
de aquí ha provenido el gran impulso dado a la educación pública desde fines del siglo último, y que ha hecho de ella una verdadera ciencia cultivada con la intención y el celo correspondientes a la magnitud del objeto o [para aprender] sabido es que la habilidad del maestro es el gran resorte de un método. ${ }^{47}$

Prueba de esta situación estancada fue la Ley de Instrucción Primaria, de 21 de julio de 1838, en la que una vez más se establecían una serie de requisitos para ser maestro, con el fin de asegurar personas formadas que impartieran enseñanza. Estos requisitos no distaban mucho de los ya establecidos en el siglo XVIII con la reforma ilustrada: haber obtenido el título correspondiente, presentar un informe de limpieza de sangre y buenas costumbres, no haber cometido delitos, etc. ${ }^{48}$ Sin embargo, estos requisitos seguían sin dotarse de la importancia que realmente tenían, puesto que

en las poblaciones donde por falta de recursos no fuese posible establecer escuela elemental completa donde se enseñe, se proveerá establecimiento, donde se enseñen las partes más indispensables como leer, escribir y doctrina cristiana por la persona que preste este servicio, «tenga o no título de maestro». ${ }^{49}$

Esta visión global se refleja con claridad en el caso de la provincia de Madrid, la cual, en general, como hemos visto, no conoce una evolución muy diferente a la del resto de provincias castellanas. Los pueblos, villas y lugares de esta provincia se comportan de manera muy distinta entre ellos, y no hemos detectado una pauta que explique por qué en determinados lugares había maestros o por qué no, más allá de los apuntes señalados. De hecho, hemos intentado buscar relaciones entre pueblos cuyos ingresos fueran muy bajos y lugares con rentas más altas para intentar explicar la existencia o no de maestros, pero no se pueden establecer causas-efectos motivadas por este punto. Lo que sí podría señalarse, y parece obvio, es que de entre los pueblos cuyos maestros ganaban muy poco por el oficio de maestro, se localizan aquellos que, o bien sus niveles de renta eran escasos, o bien tenían gastos superiores a los ingresos. Por el contrario, no se ha

\footnotetext{
${ }^{47}$ AMM, exp. 2, leg. 474, servicios.

${ }^{48}$ AMM, exp. 2, leg. 474, servicios.

${ }^{49}$ AMM, exp. 2, leg. 474, servicios.
} 
encontrado relación alguna entre entre un gran nivel de ingresos y aquellos pueblos que retribuían al maestro con un buen salario, pues hay municipios con altos recursos que o bien compartían maestro o no lo tenían.

En el caso concreto de los salarios, éstos eran generalmente insuficientes. Mientras que el salario más alto de un maestro de la provincia de Madrid era de 3.000 reales y la media estaba en los 600-700, el de un médico era de 17.000 reales o el de sacristán de 4.360. Por esta razón, a menudo, los maestros se veían obligados a ejercer otros oficios con los que poder complementar sus ingresos; incluso sería más adecuado decir que tenían otros oficios y la enseñanza les servía como ingreso adicional, pues lo que ganaban por ella era realmente poco. ${ }^{50}$ Los oficios más frecuentes a los que los maestros se dedicaban — tanto lo analizado en la provincia de Madrid como en otras provincias- eran los de sacristán o notario apostólico, dedicándose también, algunos de ellos, a otros oficios muy diversos pero menos frecuentes. ${ }^{51} \mathrm{De}$ cualquier forma, no es extremadamente representativo el número de maestros que en la provincia de Madrid ejercía varios oficios: ello sucedía tan solo en 16 de los 53 pueblos que tenían maestro, lo que resulta aún más curioso debido a que algunas de las retribuciones eran, especialmente, ridículas.

Tabla 1. Rentas de pueblos de la provincia con maestros de primeras letras

\begin{tabular}{|c|c|c|c|c|c|c|}
\hline & PUEBLO & RANGO & SEÑORÍO & $\begin{array}{c}\text { TOTAL } \\
\text { INGRESOS } \\
(\mathbf{R V})\end{array}$ & $\begin{array}{c}\text { TOTAL } \\
\text { GASTOS } \\
\text { (RV) }\end{array}$ & $\begin{array}{l}\text { FECHA DE } \\
\text { RECOGIDA DE } \\
\text { DATOS }\end{array}$ \\
\hline 1 & ÁLAMO & Villa & $\begin{array}{l}\text { Señorío: Conde } \\
\text { de Miranda }\end{array}$ & $41.910,01$ & $9.231,17$ & $\begin{array}{l}\text { Madrid, } 23 \text { de julio de } \\
1754\end{array}$ \\
\hline 2 & ALBALATE & Villa & $\begin{array}{l}\text { Señorío: Duquesa del } \\
\text { Infantado }\end{array}$ & $12.788,12$ & $9.625,32$ & $\begin{array}{l}\text { Madrid, } 30 \text { de julio de } \\
1754\end{array}$ \\
\hline 3 & ALBARES & Villa & $\begin{array}{l}\text { Señorío: Marqués de } \\
\text { Mondéjar }\end{array}$ & $8.259,00$ & $8.674,00$ & $\begin{array}{l}\text { Madrid, } 05 \text { de julio de } \\
1754\end{array}$ \\
\hline 4 & ALCOBENDAS & Aldea & $\begin{array}{l}\text { Realengo/Conde } \\
\text { de Puñonrostro }\end{array}$ & $44.284,00$ & $29.746,32$ & $\begin{array}{l}\text { Madrid, } 05 \text { de noviem- } \\
\text { bre de } 1754\end{array}$ \\
\hline 5 & ALCORCÓN & Aldea & Realengo & $40.459,00$ & $20.402,25$ & $\begin{array}{l}\text { Madrid, } 14 \text { de noviem- } \\
\text { bre de } 1754\end{array}$ \\
\hline
\end{tabular}

${ }^{50}$ La diferencia salarial tampoco era mucho mayor, pues el salario más alto por maestro era de 3.000 reales, y el de maestro con oficios simultaneados era el mismo: 3.000 reales.

${ }^{51}$ En la provincia de Madrid se localizan casos en los que además de maestro se era encargado del reloj, escribano o zapatero. En otras provincias se encuentran oficios no menos curiosos como los de cirujano, tabernero, sastre o labrador. 


\begin{tabular}{|c|c|c|c|c|c|c|}
\hline & PUEBLO & RANGO & SEÑORÍO & $\begin{array}{l}\text { TOTAL } \\
\text { INGRESOS } \\
(\mathbf{R V})\end{array}$ & $\begin{array}{c}\text { TOTAL } \\
\text { GASTOS } \\
\text { (RV) }\end{array}$ & $\begin{array}{c}\text { FECHA DE } \\
\text { RECOGIDA DE } \\
\text { DATOS }\end{array}$ \\
\hline 6 & ALHÓNDIGA & Villa & Señorío: Duque de Híjar & $1.677,00$ & $1.837,27$ & $\begin{array}{l}\text { Madrid, } 09 \text { de julio de } \\
1754\end{array}$ \\
\hline 7 & ALMOGUERA & Villa & $\begin{array}{l}\text { Señorío: Marqués } \\
\text { de Mondéjar }\end{array}$ & $7.887,25$ & $6.387,00$ & $\begin{array}{l}\text { Madrid, } 04 \text { de octubre } \\
\text { de } 1754\end{array}$ \\
\hline 8 & $\begin{array}{l}\text { ALMONACID } \\
\text { DE ZORITA }\end{array}$ & Villa & Realengo & $31.548,14$ & $35.630,21$ & $\begin{array}{l}\text { Madrid, } 07 \text { de agosto } \\
\text { de } 1754\end{array}$ \\
\hline 9 & ALOCÉN & Villa & Realengo & $3.685,00$ & $3.996,22$ & $\begin{array}{l}\text { Madrid, } 15 \text { de noviem- } \\
\text { bre de } 1754\end{array}$ \\
\hline 10 & ARAVACA & Villa & $\begin{array}{l}\text { Señorío: Marqués de } \\
\text { Aravaca }\end{array}$ & $88.538,08$ & $15.806,00$ & $\begin{array}{l}\text { Madrid, } 15 \text { de noviem- } \\
\text { bre de } 1754\end{array}$ \\
\hline 11 & AUÑÓN & Villa & $\begin{array}{l}\text { Señorío: Marqués de } \\
\text { Auñón/Conde de Clavijo }\end{array}$ & $7.685,00$ & $4.015,00$ & $\begin{array}{l}\text { Madrid, } 09 \text { de noviem- } \\
\text { bre de } 1754\end{array}$ \\
\hline 12 & BARAJAS & Villa & $\begin{array}{l}\text { Señorío: Marqués de la } \\
\text { Estepa }\end{array}$ & $42.869,00$ & $9.848,31$ & $\begin{array}{l}\text { Madrid, } 30 \text { de septiem- } \\
\text { bre de } 1754\end{array}$ \\
\hline 13 & \begin{tabular}{|l|} 
BELMONTE \\
DEL TAJO \\
\end{tabular} & Villa & $\begin{array}{l}\text { Señorío: Condesa de } \\
\text { Belmonte }\end{array}$ & $8.576,02$ & $2.164,06$ & $\begin{array}{l}\text { Madrid, } 07 \text { de octubre } \\
\text { de } 1754\end{array}$ \\
\hline 14 & BERNINCHES & Villa & $\begin{array}{l}\text { Señorío: Conde de } \\
\text { Santiago de Calimaia }\end{array}$ & $5.007,00$ & $2.182,02$ & $\begin{array}{l}\text { Madrid, } 06 \text { de noviem- } \\
\text { bre de } 1754\end{array}$ \\
\hline 15 & $\begin{array}{l}\text { BOADILLA DEL } \\
\text { MONTE }\end{array}$ & Villa & $\begin{array}{l}\text { Señorío: Marquesa de } \\
\text { Mirabal }\end{array}$ & $75.247,12$ & $9.421,00$ & $\begin{array}{l}\text { Madrid, } 29 \text { de octubre } \\
\text { de } 1754\end{array}$ \\
\hline 16 & BOROX & Villa & Realengo & $25.686,00$ & $14.511,00$ & $\begin{array}{l}\text { Madrid, } 31 \text { de julio de } \\
1754\end{array}$ \\
\hline 17 & BREA DEL TAJO & Villa & $\begin{array}{l}\text { Realengo/Marqués de } \\
\text { Mondéjar }\end{array}$ & $7.284,20$ & $4.269,24$ & $\begin{array}{l}\text { Madrid, } 26 \text { de agosto } \\
\text { de } 1754\end{array}$ \\
\hline 18 & BRUNETE & Villa & $\begin{array}{l}\text { Señorío: Duque de } \\
\text { Julliano y Marqués de } \\
\text { Francavila }\end{array}$ & $25.700,00$ & $15.965,00$ & $\begin{array}{l}\text { Madrid, } 23 \text { de septiem- } \\
\text { bre de } 1754\end{array}$ \\
\hline 19 & BUENDÍA & Villa & $\begin{array}{l}\text { Señorío: Duque } \\
\text { de Medinaceli }\end{array}$ & $23.858,00$ & $4.991,24$ & $\begin{array}{l}\text { Madrid, } 09 \text { de agosto } \\
\text { de } 1754\end{array}$ \\
\hline 20 & $\begin{array}{l}\text { CARABANCHEL } \\
\text { DE ABAJO } \\
\end{array}$ & Aldea & Realengo & $91.585,04$ & $19.259,17$ & $\begin{array}{l}\text { Madrid, } 20 \text { de julio de } \\
1754\end{array}$ \\
\hline 21 & $\begin{array}{l}\text { CARABANCHEL } \\
\text { DE ARRIBA } \\
\end{array}$ & Aldea & Realengo & $94.254,07$ & $4.980,00$ & $\begin{array}{l}\text { Madrid, } 29 \text { de julio de } \\
1754\end{array}$ \\
\hline 22 & CARMENA & Villa & $\begin{array}{l}\text { Señorío: Duque } \\
\text { de Maqueda }\end{array}$ & $21.696,00$ & $5.505,17$ & $\begin{array}{l}\text { Madrid, } 09 \text { de octubre } \\
\text { de } 1754\end{array}$ \\
\hline 23 & $\begin{array}{l}\text { CASARRUBIOS } \\
\text { DEL MONTE }\end{array}$ & Villa & $\begin{array}{l}\text { Señorío: Conde de } \\
\text { Casarrubios/Conde de } \\
\text { Miranda }\end{array}$ & $75.441,11$ & $24.839,22$ & $\begin{array}{l}\text { Madrid, } 22 \text { de mayo } \\
\text { de } 1754\end{array}$ \\
\hline 24 & ESCARICHE & Villa & Realengo & $2.351,00$ & $5.058,00$ & $\begin{array}{l}\text { Madrid, } 31 \text { de mayo } \\
\text { de } 1754\end{array}$ \\
\hline 25 & ESCOPETE & Villa & $\begin{array}{l}\text { Señorío: Duquesa del } \\
\text { Infantado }\end{array}$ & No tiene & 630,00 & $\begin{array}{l}\text { Madrid, } 27 \text { de mayo } \\
\text { de } 1754\end{array}$ \\
\hline
\end{tabular}




\begin{tabular}{|c|c|c|c|c|c|c|}
\hline & PUEBLO & RANGO & SEÑORÍO & $\begin{array}{l}\text { TOTAL } \\
\text { INGRESOS } \\
(\mathbf{R V})\end{array}$ & $\begin{array}{c}\text { TOTAL } \\
\text { GASTOS } \\
\text { (RV) }\end{array}$ & $\begin{array}{c}\text { FECHA DE } \\
\text { RECOGIDA DE } \\
\text { DATOS }\end{array}$ \\
\hline 26 & FUENCARRAL & Aldea & Realengo & $73.042,00$ & $26.027,00$ & $\begin{array}{l}\text { Madrid, } 07 \text { de junio } \\
\text { de } 1754\end{array}$ \\
\hline 27 & FUENLABRADA & Aldea & Realengo & $33.222,01$ & $3.601,05$ & $\begin{array}{l}\text { Madrid, } 27 \text { de septiem- } \\
\text { bre de } 1754\end{array}$ \\
\hline 28 & $\begin{array}{l}\text { FUENTELEN- } \\
\text { CINA }\end{array}$ & Villa & Realengo & $8.949,33$ & $7.152,28$ & $\begin{array}{l}\text { Madrid, } 14 \text { de agosto } \\
\text { de } 1754\end{array}$ \\
\hline 29 & GRIÑON & Villa & $\begin{array}{l}\text { Señorío: Marqués de } \\
\text { Malpica }\end{array}$ & $6.362,05$ & $5.447,04$ & $\begin{array}{l}\text { Madrid, } 12 \text { de junio } \\
\text { de } 1754\end{array}$ \\
\hline 30 & HONTOBA & Villa & Realengo/Calatrava & $2.727,02$ & $3.265,31$ & $\begin{array}{l}\text { Madrid, } 12 \text { de junio } \\
\text { de } 1754\end{array}$ \\
\hline 31 & HORTALEZA & Villa & $\begin{array}{l}\text { Señorío: Conde } \\
\text { de Salvatierra }\end{array}$ & $18.064,11$ & $3.895,00$ & $\begin{array}{l}\text { Madrid, } 11 \text { de junio } \\
\text { de } 1754\end{array}$ \\
\hline 32 & HUEVA & Villa & Realengo & $2.233,00$ & $2.274,05$ & $\begin{array}{l}\text { Madrid, } 11 \text { de junio } \\
\text { de } 1754\end{array}$ \\
\hline 33 & ILLANA & Villa & $\begin{array}{l}\text { Señorío: Marqués de } \\
\text { Belzunce (Goyeneche) }\end{array}$ & $16.886,22$ & $6.927,16$ & $\begin{array}{l}\text { Madrid, } 09 \text { de septiem- } \\
\text { bre de } 1754\end{array}$ \\
\hline 34 & LEGANÉS & Villa & $\begin{array}{l}\text { Señorío: Conde } \\
\text { de Altamira }\end{array}$ & $110.057,00$ & $52.793,17$ & $\begin{array}{l}\text { Madrid, } 28 \text { de junio } \\
\text { de } 1754\end{array}$ \\
\hline 35 & MAZUECOS & Villa & $\begin{array}{l}\text { Señorío: Marqués } \\
\text { de Mondéjar }\end{array}$ & $3.854,05$ & $2.605,17$ & $\begin{array}{l}\text { Madrid, } 29 \text { de agosto } \\
\text { de } 1754\end{array}$ \\
\hline 36 & $\begin{array}{l}\text { MORALEJA LA } \\
\text { DE ENMEDIO }\end{array}$ & Villa & $\begin{array}{l}\text { Señorío: Infante } \\
\text { Don Phelipe }\end{array}$ & $12.444,00$ & 160,00 & $\begin{array}{l}\text { Madrid, } 08 \text { de junio } \\
\text { de } 1754\end{array}$ \\
\hline 37 & MORATILLA & Villa & Realengo & $7.495,21$ & $4.541,14$ & $\begin{array}{l}\text { Madrid, } 10 \text { de junio } \\
\text { de } 1754\end{array}$ \\
\hline 38 & PARLA & Villa & $\begin{array}{l}\text { Señorío: Marqués } \\
\text { de Malpica }\end{array}$ & $23.568,05$ & $10.751,17$ & $\begin{array}{l}\text { Madrid, } 15 \text { de septiem- } \\
\text { bre de } 1754\end{array}$ \\
\hline 39 & PASTRANA & Villa & $\begin{array}{l}\text { Señorío: Duquesa } \\
\text { del Infantado }\end{array}$ & $25.511,25$ & $33.743,08$ & $\begin{array}{l}\text { Madrid, } 29 \text { de junio } \\
\text { de } 1754\end{array}$ \\
\hline 40 & PEÑALVER & Villa & $\begin{array}{l}\text { Señorío: Duque } \\
\text { de Híjar }\end{array}$ & $3.457,31$ & $3.610,00$ & $\begin{array}{l}\text { Madrid, } 15 \text { de junio } \\
\text { de } 1754\end{array}$ \\
\hline 41 & POZUELO & Villa & $\begin{array}{l}\text { Señorío: Conde de } \\
\text { Cazalla del Río }\end{array}$ & $35.770,00$ & $8.648,00$ & $\begin{array}{l}\text { Madrid, } 18 \text { de septiem- } \\
\text { bre de } 1754\end{array}$ \\
\hline 42 & QUISMONDO & Villa & $\begin{array}{l}\text { Señorío: Duque de } \\
\text { Maqueda }\end{array}$ & $6.320,00$ & $9.755,00$ & $\begin{array}{l}\text { Madrid, } 26 \text { de junio } \\
\text { de } 1754\end{array}$ \\
\hline 43 & ROZAS & Aldea & Realengo & $60.629,03$ & $21.606,00$ & $\begin{array}{l}\text { Madrid, } 12 \text { de septiem- } \\
\text { bre de } 1754\end{array}$ \\
\hline 44 & $\begin{array}{l}\text { SAN AGUSTÍN } \\
\text { DE GUADALIX }\end{array}$ & Villa & $\begin{array}{l}\text { Señorío: Conde } \\
\text { de Puñonrostro }\end{array}$ & $39.597,17$ & $13.836,00$ & $\begin{array}{l}\text { Madrid, } 02 \text { de octubre } \\
\text { de } 1754\end{array}$ \\
\hline 45 & $\begin{array}{l}\text { SAN SEBASTIÁN } \\
\text { DE LOS REYES }\end{array}$ & Aldea & Realengo & $41.665,08$ & $17.521,17$ & $\begin{array}{l}\text { Madrid, } 06 \text { de junio } \\
\text { de } 1754\end{array}$ \\
\hline 46 & $\begin{array}{l}\text { SANTA CRUZ } \\
\text { DE RETAMAR }\end{array}$ & Villa & $\begin{array}{l}\text { Señorío: Duque } \\
\text { de Maqueda }\end{array}$ & $10.670,00$ & $3.670,00$ & $\begin{array}{l}\text { Madrid, } 22 \text { de junio } \\
\text { de } 1754\end{array}$ \\
\hline
\end{tabular}




\begin{tabular}{|c|c|c|c|c|c|c|}
\hline & PUEBLO & RANGO & SEÑORÍO & $\begin{array}{c}\text { TOTAL } \\
\text { INGRESOS } \\
\text { (RV) }\end{array}$ & $\begin{array}{c}\text { TOTAL } \\
\text { GASTOS } \\
(\text { RV })\end{array}$ & $\begin{array}{c}\text { FECHA DE } \\
\text { RECOGIDA DE } \\
\text { DATOS }\end{array}$ \\
\hline 47 & SERRANILLOS & Villa & \begin{tabular}{|l|} 
Señorío: Infante \\
Don Phelipe
\end{tabular} & $3.602,06$ & $3.460,00$ & $\begin{array}{l}\text { Madrid, } 25 \text { de junio } \\
\text { de } 1754\end{array}$ \\
\hline 48 & $\begin{array}{l}\text { TORREJÓN DE } \\
\text { VELASCO }\end{array}$ & Villa & $\begin{array}{l}\text { Señorío: Conde } \\
\text { de Puñonrostro }\end{array}$ & $4.080,00$ & $10.870,00$ & $\begin{array}{l}\text { Madrid, } 27 \text { de junio } \\
\text { de } 1754\end{array}$ \\
\hline 49 & VALDECONCHA & Villa & $\begin{array}{l}\text { Señorío: Duque Francisco } \\
\text { M. de Rivadeneyra }\end{array}$ & $7.587,24$ & $6.003,24$ & $\begin{array}{l}\text { Madrid, } 20 \text { de septiem- } \\
\text { bre de } 1754\end{array}$ \\
\hline 50 & VALLECAS & Aldea & Realengo & $85.481,28$ & $62.825,17$ & $\begin{array}{l}\text { Madrid, } 25 \text { de septiem- } \\
\text { bre de } 1754\end{array}$ \\
\hline 51 & VICÁLVARO & Aldea & Realengo & $91.259,17$ & $20.562,00$ & $\begin{array}{l}\text { Madrid, } 12 \text { de julio de } \\
1754\end{array}$ \\
\hline 52 & VILLAVERDE & Aldea & Realengo & $40.224,06$ & $14.841,00$ & $\begin{array}{l}\text { Madrid, } 02 \text { de septiem- } \\
\text { bre de } 1754\end{array}$ \\
\hline 53 & YEBRA & Villa & $\begin{array}{l}\text { Señorío: don Carlos } \\
\text { Bratuti }\end{array}$ & $21.840,04$ & $2.929,22$ & $\begin{array}{l}\text { Madrid, } 10 \text { de septiem- } \\
\text { bre de } 1754\end{array}$ \\
\hline
\end{tabular}

Fuente: elaboración propia a partir de los datos extraídos del libro de Concepción Camarero Bullón, Madrid y su provincia en el Catastro de Ensenada. II. Los pueblos de Madrid (1750-1759) (Madrid: Ediciones del Umbral, 2005).

Tabla 2: Rentas de pueblos de la provincia sin maestros de primeras letras

\begin{tabular}{|c|c|c|c|c|c|c|}
\hline & PUEBLO & RANGO & SEÑORÍO & $\begin{array}{l}\text { TOTAL } \\
\text { INGRESOS } \\
\text { (RV) }\end{array}$ & $\begin{array}{l}\text { TOTAL } \\
\text { GASTOS } \\
\text { (RV) }\end{array}$ & $\begin{array}{l}\text { FECHA DE } \\
\text { RECOGIDA DE } \\
\text { DATOS }\end{array}$ \\
\hline 1 & ALAMEDA & Villa & $\begin{array}{l}\text { Señorío: Conde de } \\
\text { Barajas }\end{array}$ & $13.300,00$ & $5.181,04$ & $\begin{array}{l}\text { Madrid, } 03 \text { de } \\
\text { julio de } 1754\end{array}$ \\
\hline 2 & AMBROZ & Aldea & Realengo & $8.368,00$ & $3.170,17$ & $\begin{array}{l}\text { Madrid, } 13 \text { de no- } \\
\text { viembre de } 1754\end{array}$ \\
\hline 3 & ANGUIX & Despoblado & $\begin{array}{l}\text { Señorío: Marqués de } \\
\text { Mondéjar }\end{array}$ & & & \\
\hline 4 & ARROYOMOLINOS & Villa & $\begin{array}{l}\text { Señorío: Conde de } \\
\text { Miranda }\end{array}$ & $4.926,00$ & $2.319,00$ & $\begin{array}{l}\text { Madrid, } 11 \text { de no- } \\
\text { viembre de } 1754\end{array}$ \\
\hline 5 & CANILLAS & Villa & $\begin{array}{l}\text { Señorío: Conde de } \\
\text { Canillas }\end{array}$ & $10.151,00$ & $4.191,01$ & $\begin{array}{l}\text { Madrid, } 12 \text { de } \\
\text { octubre de } 1754\end{array}$ \\
\hline 6 & CANILLEJAS & Villa & $\begin{array}{l}\text { Señorío: Conde de } \\
\text { Canillejas }\end{array}$ & $13.105,00$ & $2.077,07$ & $\begin{array}{l}\text { Madrid, } 15 \text { de } \\
\text { octubre de } 1754\end{array}$ \\
\hline 7 & $\begin{array}{l}\text { CASARRUBUE- } \\
\text { LOS }\end{array}$ & Aldea & Realengo & $3.600,00$ & $2.798,00$ & $\begin{array}{l}\text { Madrid, } 17 \text { de } \\
\text { octubre de } 1754\end{array}$ \\
\hline 8 & CHAMARTÍN & Villa & $\begin{array}{l}\text { Señorío: Duquesa del } \\
\text { Infantado }\end{array}$ & $17.088,20$ & $4.600,00$ & $\begin{array}{l}\text { Madrid, } 04 \text { de } \\
\text { septiembre de } \\
1754\end{array}$ \\
\hline
\end{tabular}




\begin{tabular}{|c|c|c|c|c|c|c|}
\hline & PUEBLO & RANGO & SEÑORÍO & $\begin{array}{c}\text { TOTAL } \\
\text { INGRESOS } \\
(\mathbf{R V})\end{array}$ & $\begin{array}{c}\text { TOTAL } \\
\text { GASTOS } \\
(\mathbf{R V})\end{array}$ & $\begin{array}{c}\text { FECHA DE } \\
\text { RECOGIDA DE } \\
\text { DATOS }\end{array}$ \\
\hline 9 & COSLADA & Villa & $\begin{array}{l}\text { Señorío: Marqués de } \\
\text { la Estepa }\end{array}$ & $8.325,17$ & $2.453,00$ & $\begin{array}{l}\text { Madrid, } 25 \text { de } \\
\text { mayo de } 1754\end{array}$ \\
\hline 10 & CUBAS & Villa & $\begin{array}{l}\text { Señorío: Marqués de } \\
\text { Malpica }\end{array}$ & $4.011,06$ & $5.066,06$ & $\begin{array}{l}\text { Madrid, } 15 \text { de } \\
\text { julio de } 1754\end{array}$ \\
\hline 11 & DRIEBES & Villa & $\begin{array}{l}\text { Realengo/Marqués de } \\
\text { Mondéjar }\end{array}$ & $4.936,00$ & $2.659,00$ & $\begin{array}{l}\text { Madrid, } 29 \text { de } \\
\text { mayo } 1754\end{array}$ \\
\hline 12 & $\begin{array}{l}\text { EL CAMPO DE } \\
\text { MADRID }\end{array}$ & Villa & Realengo & & & \\
\hline 13 & $\begin{array}{l}\text { EL COMÚN DEL } \\
\text { LAS ONCE } \\
\text { VILLAS } \\
\end{array}$ & Despoblado & $\begin{array}{l}\text { Señorío: Duquesa del } \\
\text { Infantado }\end{array}$ & & & \\
\hline 14 & \begin{tabular}{|l|} 
FUENTE EL \\
FRESNO \\
\end{tabular} & Aldea & Realengo & $23.047,00$ & $4.475,00$ & $\begin{array}{l}\text { Madrid, } 24 \text { de } \\
\text { julio de } 1754\end{array}$ \\
\hline 15 & FUENTENOVILLA & Villa & $\begin{array}{l}\text { Señorío: Marqués de } \\
\text { Mondéjar }\end{array}$ & $7.537,22$ & $3.212,11$ & $\begin{array}{l}\text { Madrid, } 04 \text { de } \\
\text { junio de } 1754\end{array}$ \\
\hline 16 & GETAFE & Aldea & Realengo & $124.443,04$ & $72.188,18$ & \begin{tabular}{|l|} 
Madrid, $07 \mathrm{de}$ \\
junio de 1754
\end{tabular} \\
\hline 17 & HUMANEJOS & Aldea & Realengo & & & \\
\hline 18 & HÚMERA & Villa & $\begin{array}{l}\text { Señorío: D. Juan } \\
\text { Nicolás de Molina }\end{array}$ & 960,00 & No tiene & \begin{tabular}{|l} 
Madrid, 12 de \\
agosto de 1754
\end{tabular} \\
\hline 19 & LA PANGÍA & Despoblado & $\begin{array}{l}\text { Señorío: Duquesa del } \\
\text { Infantado }\end{array}$ & & & \\
\hline 20 & MAJADAHONDA & Aldea & Realengo & $28.785,00$ & $9.485,00$ & $\begin{array}{l}\text { Madrid, } 27 \text { de } \\
\text { julio de } 1754\end{array}$ \\
\hline 21 & MAQUEDA & Villa & $\begin{array}{l}\text { Señorío: Duque de } \\
\text { Maqueda }\end{array}$ & $31.496,32$ & $8.292,00$ & $\begin{array}{l}\text { Madrid, } 10 \text { de } \\
\text { junio de } 1754\end{array}$ \\
\hline 22 & MEJORADA & Villa & $\begin{array}{l}\text { Señorío: Marqués } \\
\text { de Mejorada }\end{array}$ & $10.597,17$ & 99,00 & $\begin{array}{l}\text { Madrid, } 10 \text { de } \\
\text { junio de } 1754\end{array}$ \\
\hline 23 & $\begin{array}{l}\text { MORALEJA LA } \\
\text { MAYOR }\end{array}$ & Villa & $\begin{array}{l}\text { Señorío: Infante } \\
\text { Don Phelipe }\end{array}$ & $2.784,00$ & 40,17 & $\begin{array}{l}\text { Madrid, } 17 \text { de } \\
\text { agosto de } 1754\end{array}$ \\
\hline 24 & PEDREZUELA & Villa & $\begin{array}{l}\text { Señorío: Conde de } \\
\text { Puñonrostro }\end{array}$ & $69.769,00$ & $3.189,00$ & $\begin{array}{l}\text { Madrid, } 21 \text { de } \\
\text { agosto de } 1754\end{array}$ \\
\hline 25 & $\begin{array}{l}\text { PERALES DEL } \\
\text { RÍO } \\
\end{array}$ & Villa & $\begin{array}{l}\text { Señorío: Marqués } \\
\text { de Perales }\end{array}$ & $3.300,00$ & No tiene & \begin{tabular}{|l|} 
Madrid, 28 de \\
junio de 1754
\end{tabular} \\
\hline 26 & POLVORANCA & Villa & $\begin{array}{l}\text { Señorío: Marqués } \\
\text { de los Palacios }\end{array}$ & \multicolumn{3}{|c|}{$\begin{array}{l}\text { "No consta tener propios, cargas, arvitrios ni } \\
\text { sisas" Martín de Abarrategui }\end{array}$} \\
\hline 27 & \begin{tabular}{|l|} 
POZO DE \\
ALMOGUERA
\end{tabular} & Villa & $\begin{array}{l}\text { Señorío: Marqués } \\
\text { de Mondéjar }\end{array}$ & $1.157,16$ & 662,14 & $\begin{array}{l}\text { Madrid, } 14 \text { de } \\
\text { junio de } 1754\end{array}$ \\
\hline 28 & QUIJORNA & Villa & $\begin{array}{l}\text { Señorío: Duque de } \\
\text { Julliano y Marq. de } \\
\text { Francavila }\end{array}$ & $17.405,01$ & $8.044,00$ & $\begin{array}{l}\text { Madrid, } 14 \text { de } \\
\text { junio de } 1754\end{array}$ \\
\hline 29 & $\begin{array}{l}\text { REAL CASA } \\
\text { Y SITIO } \\
\text { DE GÓZQUEZ }\end{array}$ & Real Sitio & $\begin{array}{l}\text { Monasterio } \\
\text { El Escorial }\end{array}$ & & & \\
\hline
\end{tabular}




\begin{tabular}{|c|c|c|c|c|c|c|}
\hline & PUEBLO & RANGO & SEÑORÍO & $\begin{array}{c}\text { TOTAL } \\
\text { INGRESOS } \\
(\mathbf{R V})\end{array}$ & $\begin{array}{l}\text { TOTAL } \\
\text { GASTOS } \\
(\text { RV) }\end{array}$ & $\begin{array}{c}\text { FECHA DE } \\
\text { RECOGIDA DE } \\
\text { DATOS } \\
\end{array}$ \\
\hline 30 & REJAS & Villa & $\begin{array}{l}\text { Señorío: Marqués de } \\
\text { la Estepa }\end{array}$ & $17.950,00$ & $4.600,00$ & $\begin{array}{l}\text { Madrid, } 27 \text { de } \\
\text { junio de } 1754\end{array}$ \\
\hline 31 & RIVAS & Villa & $\begin{array}{l}\text { Señorío: Marqués de } \\
\text { Rivas }\end{array}$ & $1.960,00$ & 410,00 & $\begin{array}{l}\text { Madrid, } 21 \text { de } \\
\text { junio de } 1754\end{array}$ \\
\hline 32 & ROMANILLOS & Villa & $\begin{array}{l}\text { Señorío: Suc. De } \\
\text { D. Pedro Gallo }\end{array}$ & & & \\
\hline 33 & $\begin{array}{l}\text { SACEDÓN (DE } \\
\text { LOS CANALES) }\end{array}$ & Villa & $\begin{array}{l}\text { Señorío: Infante } \\
\text { Don Phelipe }\end{array}$ & $8.148,19$ & $2.611,14$ & $\begin{array}{l}\text { Madrid, } 15 \text { de } \\
\text { junio de } 1754\end{array}$ \\
\hline 34 & SAYATÓN & Villa & $\begin{array}{l}\text { Señorío: Duquesa del } \\
\text { Infantado }\end{array}$ & $3.361,00$ & $3.503,00$ & $\begin{array}{l}\text { Madrid, } 20 \text { de } \\
\text { junio de } 1754\end{array}$ \\
\hline 35 & SEVER & Despoblado & $\begin{array}{l}\text { Señorío: Duquesa del } \\
\text { Infantado }\end{array}$ & & & \\
\hline 36 & $\begin{array}{l}\text { TORREJÓN DE } \\
\text { LA CALZADA }\end{array}$ & Aldea & Realengo & $4.085,00$ & $1.773,00$ & $\begin{array}{l}\text { Madrid, } 05 \text { de } \\
\text { agosto de } 1754\end{array}$ \\
\hline 37 & VACIAMADRID & Villa & $\begin{array}{l}\text { Señorío: Conde de } \\
\text { Altamira }\end{array}$ & $5.209,10$ & $\begin{array}{l}\text { Satisfechos } \\
\text { por el } \\
\text { conde }\end{array}$ & $\begin{array}{l}\text { Madrid, } 14 \text { de } \\
\text { septiembre de } \\
1754\end{array}$ \\
\hline 38 & $\begin{array}{l}\text { VAL DE SANTO } \\
\text { DOMINGO }\end{array}$ & Villa & $\begin{array}{l}\text { Señorío: Duque de } \\
\text { Maqueda }\end{array}$ & $78.566,14$ & $21.142,17$ & $\begin{array}{l}\text { Madrid, } 22 \text { de oc- } \\
\text { tubre de } 1754\end{array}$ \\
\hline 39 & VALDECANAL & Despoblado & $\begin{array}{l}\text { Señorío: Duquesa del } \\
\text { Infantado }\end{array}$ & & & \\
\hline 40 & $\begin{array}{l}\text { VALLES Y } \\
\text { CABANILLAS }\end{array}$ & Despoblado & $\begin{array}{l}\text { Señorío: Duquesa del } \\
\text { Infantado }\end{array}$ & & & \\
\hline 41 & VALMOJADO & Villa & $\begin{array}{l}\text { Señorío: Conde de } \\
\text { Miranda }\end{array}$ & $7.425,00$ & $3.509,00$ & $\begin{array}{l}\text { Madrid, } 26 \text { de oc- } \\
\text { tubre de } 1754\end{array}$ \\
\hline 42 & $\begin{array}{l}\text { VELILLA DE SAN } \\
\text { ANTONIO }\end{array}$ & Villa & $\begin{array}{l}\text { Señorío: X. Díaz } \\
\text { Ramos de Velasco }\end{array}$ & $2.325,00$ & $1.473,00$ & $\begin{array}{l}\text { Madrid, } 24 \text { de oc- } \\
\text { tubre de } 1754\end{array}$ \\
\hline 43 & $\begin{array}{l}\text { VENTAS DE } \\
\text { RETAMOSA }\end{array}$ & Villa & $\begin{array}{l}\text { Señorío: Conde } \\
\text { de Miranda }\end{array}$ & $6.383,11$ & $10.160,00$ & $\begin{array}{l}\text { Madrid, } 06 \text { de } \\
\text { septiembre de } \\
1754\end{array}$ \\
\hline 44 & $\begin{array}{l}\text { VILLA DE ODÓN } \\
\text { O VILLAVICIOSA }\end{array}$ & Villa & $\begin{array}{l}\text { Señorío: Infante Don } \\
\text { Phelipe }\end{array}$ & $25.586,00$ & $5.906,00$ & $\begin{array}{l}\text { Madrid, } 10 \text { de } \\
\text { junio de } 1754\end{array}$ \\
\hline 45 & VILLAMANTA & Villa & $\begin{array}{l}\text { Señorío: Conde de } \\
\text { Miranda }\end{array}$ & $11.581,17$ & $12.832,00$ & $\begin{array}{l}\text { Madrid, } 05 \text { de } \\
\text { junio de } 1754\end{array}$ \\
\hline 46 & $\begin{array}{l}\text { ZORITA DE LOS } \\
\text { CANES }\end{array}$ & Villa & $\begin{array}{l}\text { Señorío: D. Luis A. } \\
\text { Curiel Álamo y } \\
\text { Miranda }\end{array}$ & 714,00 & 432,14 & $\begin{array}{l}\text { Madrid, } 24 \text { de ma- } \\
\text { yo de } 1754\end{array}$ \\
\hline
\end{tabular}

Fuente: elaboración propia a partir de los datos extraídos del libro de Concepción Camarero Bullón, Madrid y su provincia en el Catastro de Ensenada. II Los pueblos de Madrid (1750-1759). (Madrid: Ediciones del Umbral, 2005). 


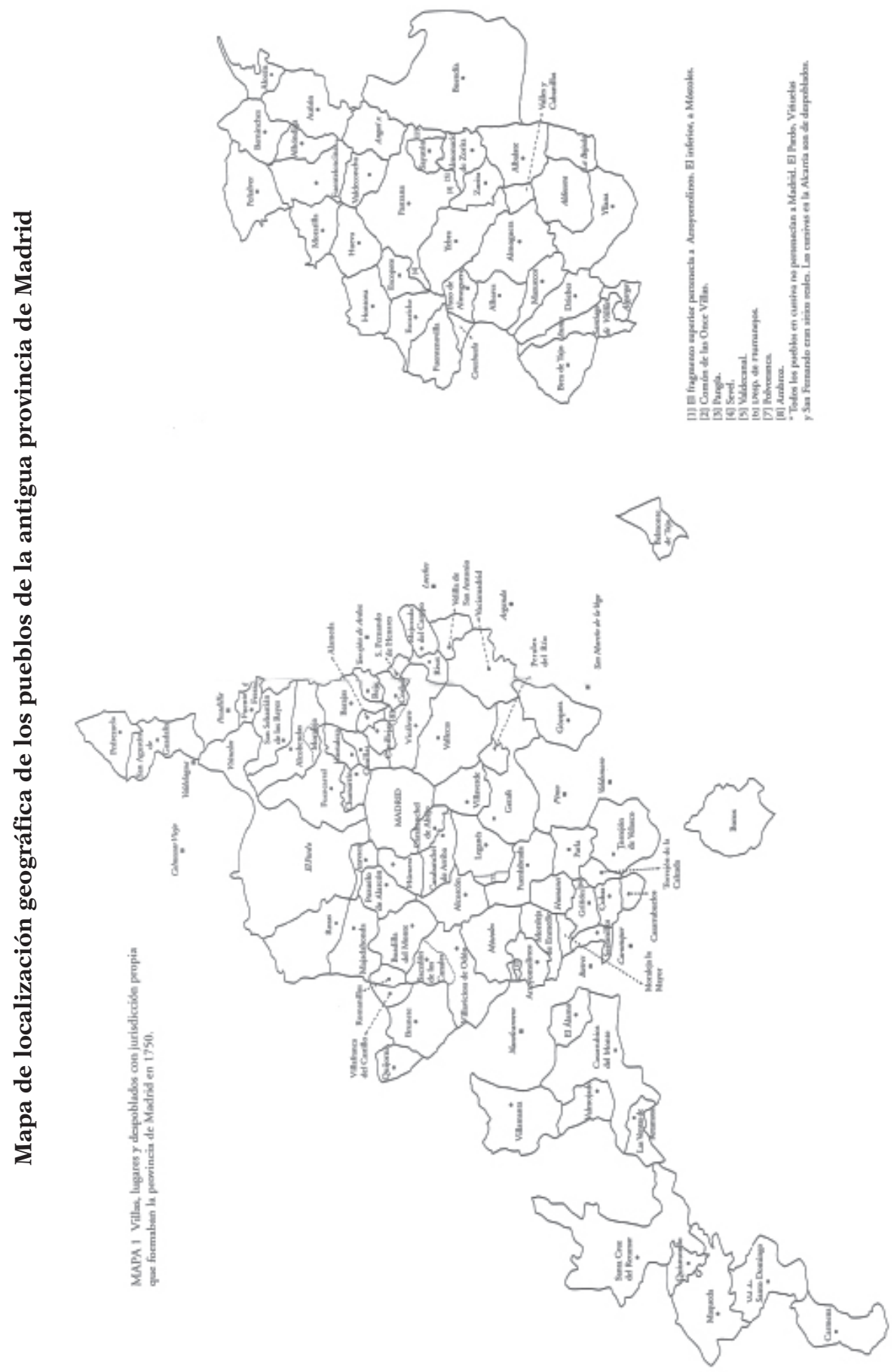


Tabla 3: Retribuciones aproximadas del oficio de maestro de primeras letras

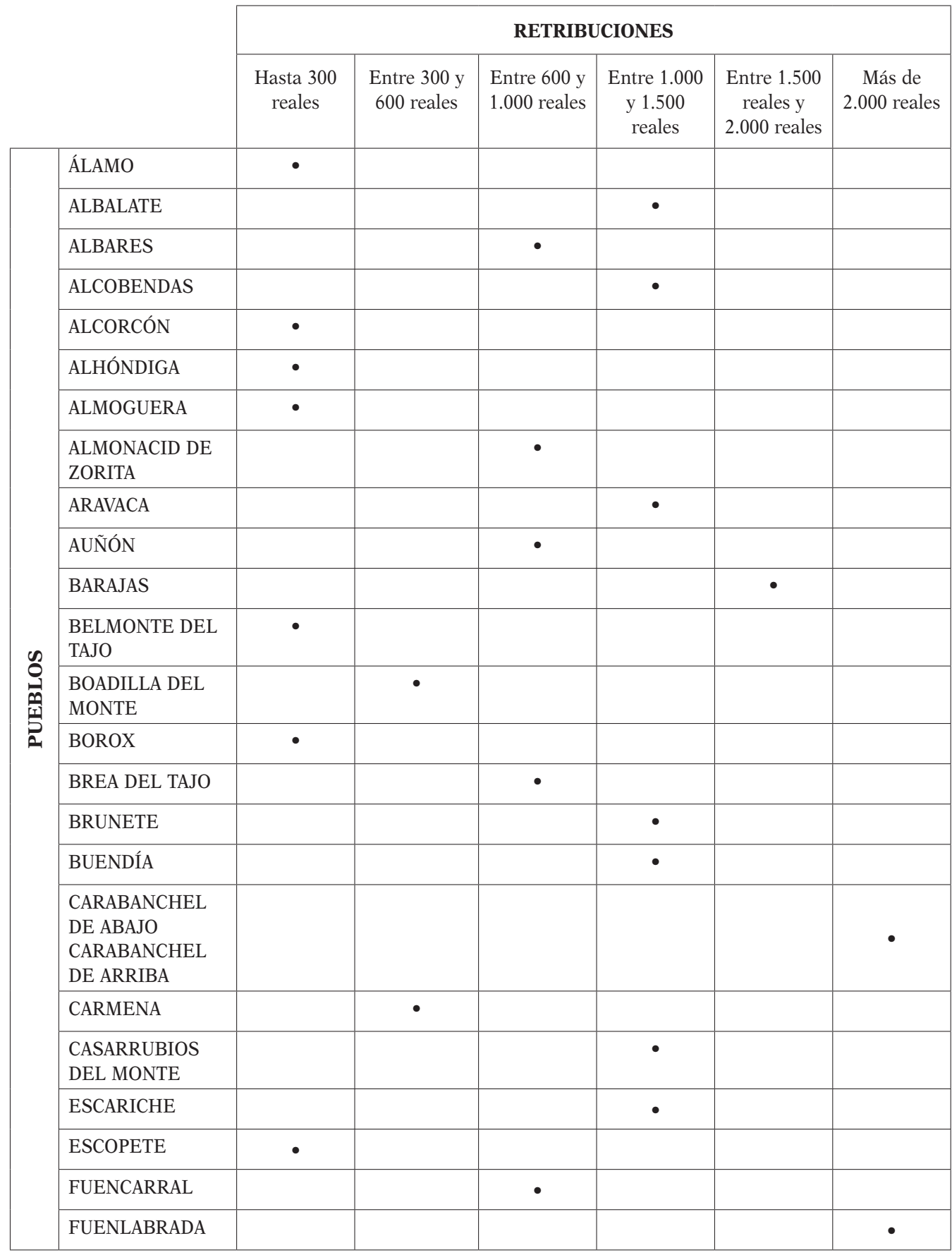




\begin{tabular}{|c|c|c|c|c|c|c|c|}
\hline & \multicolumn{6}{|c|}{ RETRIBUCIONES } \\
\hline & & $\begin{array}{c}\text { Hasta } 300 \\
\text { reales }\end{array}$ & $\begin{array}{c}\text { Entre } 300 \mathrm{y} \\
600 \text { reales }\end{array}$ & $\begin{array}{l}\text { Entre } 600 \mathrm{y} \\
1.000 \text { reales }\end{array}$ & $\begin{array}{c}\text { Entre } 1.000 \\
\text { y } 1.500 \\
\text { reales }\end{array}$ & $\begin{array}{c}\text { Entre } 1.500 \\
\quad \text { reales y } \\
2.000 \text { reales }\end{array}$ & $\begin{array}{c}\text { Más de } \\
2.000 \text { reales }\end{array}$ \\
\hline \multirow{24}{*}{ 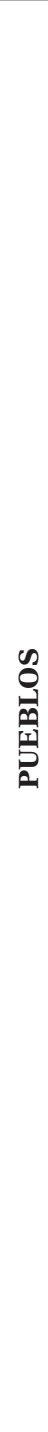 } & FUENTELENCINA & & & & $\bullet$ & & \\
\hline & GRIÑÓN & & - & & & & \\
\hline & HONTOBA & & & - & & & \\
\hline & HORTALEZA & & & - & & & \\
\hline & HUEVA & $\bullet$ & & & & & \\
\hline & ILLANA & & & - & & & \\
\hline & LEGANÉS & & & & & $\bullet$ & \\
\hline & MAZUECOS & & - & & & & \\
\hline & MORATILLA & & - & & & & \\
\hline & PARLA & & & - & & & \\
\hline & PASTRANA & & & & & - & \\
\hline & PEÑALVER & $\bullet$ & & & & & \\
\hline & POZUELO & & & - & & & \\
\hline & QUISMONDO & & & - & & & \\
\hline & ROZAS & & - & & & & \\
\hline & $\begin{array}{l}\text { SAN AGUSTÍN DE } \\
\text { GUADALIX }\end{array}$ & & & & & & - \\
\hline & $\begin{array}{l}\text { SANTA CRUZ DE } \\
\text { RETAMAR }\end{array}$ & - & & & & & \\
\hline & SERRANILLOS & - & & & & & \\
\hline & $\begin{array}{l}\text { TORREJÓN DE } \\
\text { VELASCO }\end{array}$ & & & & - & & \\
\hline & VALDECONCHA & & & - & & & \\
\hline & VALLECAS & & & & & $\bullet \bullet$ & \\
\hline & VICÁLVARO & & & - & & & \\
\hline & VILLAVERDE & & •. & & & & \\
\hline & YEBRA & & & - & & & \\
\hline
\end{tabular}

Fuente: elaboración propia a partir de las Respuestas generales del Catastro de Ensenada.

${ }^{52}$ La ubicación de Mazuecos en la ganancia de entre 300 y 600 reales, puede no ser del todo exacta, debido a que las Respuestas generales no dan una cifra exacta de lo que gana el maestro por emolumentos; por lo que la ubicación en la tabla se ha hecho de acuerdo a lo que le retribuye el Común. 
Tabla 4: Retribuciones de los oficios simultaneados de los maestros de primeras letras

\begin{tabular}{|c|c|c|c|c|c|c|c|c|c|}
\hline & \multicolumn{8}{|c|}{ RETRIBUCIONES } \\
\hline & & MAESTRO & SACRISTÁN & \begin{tabular}{|c|} 
NOTARIO \\
APOSTÓ- \\
LICO
\end{tabular} & $\begin{array}{l}\text { FIEL DE } \\
\text { FECHOS }\end{array}$ & $\begin{array}{l}\text { ENCAR- } \\
\text { GADO } \\
\text { DEL RE- } \\
\text { LOJ }\end{array}$ & $\begin{array}{l}\text { ZAPA- } \\
\text { TERO }\end{array}$ & $\begin{array}{l}\text { ENSEÑAR } \\
\text { DOCTRINA }\end{array}$ & TOTAL \\
\hline \multirow{26}{*}{ 兽 } & ÁLAMO & 200 & & & & & & & 200 \\
\hline & ALBALATE & 1.272 & & 100 & & & & & 1.372 \\
\hline & ALBARES & 900 & & & & & & & 900 \\
\hline & ALCOBENDAS & 1.200 & & & & & & & 1.200 \\
\hline & ALCORCÓN & 2.031 & & & & & 2.231 & & \\
\hline & ALHÓNDIGA & 200 & 1.010 & 40 & & 50 & & & 1.300 \\
\hline & ALMOGUERA & 200 & & 2.190 & & & & & 2.390 \\
\hline & $\begin{array}{l}\text { ALMONACID } \\
\text { DE ZORITA }\end{array}$ & 990 & & & & 110 & & & 1.100 \\
\hline & ALOCÉN & $\bullet$ & $\bullet$ & $\bullet$ & & & & & 991 \\
\hline & ARAVACA & $\begin{array}{c}100 \\
\text { ducados }\end{array}$ & & & & & & & $\begin{array}{c}100 \\
\text { ducados }\end{array}$ \\
\hline & AUÑÓN & 800 & 635 & 100 & 487 & & & & 2.022 \\
\hline & BARAJAS & 1.600 & & & & & & & 1.600 \\
\hline & $\begin{array}{l}\text { BELMONTE DEL } \\
\text { TAJO }\end{array}$ & 300 & 1.733 & & & 75 & & & 2.108 \\
\hline & BERNINCHES & $\bullet$ & & $\bullet$ & & & & $\bullet$ & 562 \\
\hline & $\begin{array}{l}\text { BOADILLA DEL } \\
\text { MONTE }\end{array}$ & 500 & & & & & & & 500 \\
\hline & BOROX & 150 & \multicolumn{6}{|c|}{ (era pensionista y por ello la Hacienda le pagaba 1.800 reales) } & 1.950 \\
\hline & BREA DEL TAJO & 844 & & & & & & & 844 \\
\hline & BRUNETE & 1.500 & & & & & & & 1.500 \\
\hline & BUENDÍA & 1.100 & & & & & & & 1.100 \\
\hline & $\begin{array}{l}\text { CARABANCHEL } \\
\text { DE ABAJO } \\
\text { CARABANCHEL } \\
\text { DE ARRIBA }\end{array}$ & 2.081 & & & & & & & 2.081 \\
\hline & CARMENA & 520 & & & & & & & 520 \\
\hline & $\begin{array}{l}\text { CASARRUBIOS } \\
\text { DEL MONTE }\end{array}$ & 1.450 & & & & & & & 1.450 \\
\hline & ESCARICHE & 1.320 & & & & & & & 1.320 \\
\hline & ESCOPETE & 30 & 205,23 & 20 & & & & & 255,23 \\
\hline & FUENCARRAL & 900 & & & & & & & 900 \\
\hline & FUENLABRADA & 3.000 & & & & & & & 3.000 \\
\hline
\end{tabular}




\begin{tabular}{|c|c|c|c|c|c|c|c|c|c|}
\hline & \multicolumn{8}{|c|}{ RETRIBUCIONES } \\
\hline & & MAESTRO & SACRISTÁN & $\begin{array}{l}\text { NOTARIO } \\
\text { APOSTÓ- } \\
\text { LICO }\end{array}$ & $\begin{array}{l}\text { FIEL DE } \\
\text { FECHOS }\end{array}$ & $\begin{array}{l}\text { ENCAR- } \\
\text { GADO } \\
\text { DEL RE- } \\
\text { LOJ }\end{array}$ & $\begin{array}{l}\text { ZAPA- } \\
\text { TERO }\end{array}$ & $\begin{array}{l}\text { ENSEÑAR } \\
\text { DOCTRINA }\end{array}$ & TOTAL \\
\hline \multirow{28}{*}{ 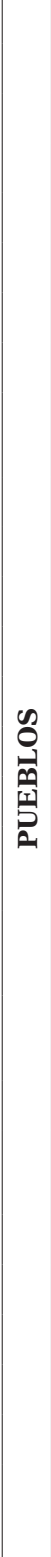 } & FUENTELENCINA & 1.165 & & & & & & & 1.165 \\
\hline & GRIÑÓN & 565 & & & & & & & 565 \\
\hline & HONTOBA & 680 & & & & 40 & & 40 & 760 \\
\hline & HORTALEZA & 700 & & & & & & & 700 \\
\hline & HUEVA & 222 & 582 & & & & & & \\
\hline & ILLANA & 1.000 & & & & & & & 1.000 \\
\hline & LEGANÉS & 1.800 & & & & & & & 1.800 \\
\hline & MAZUECOS & 500 & & & & & & & 500 \\
\hline & $\begin{array}{l}\text { MORALEJA LA } \\
\text { DE EN MEDIO }\end{array}$ & - & & & & & - & & \\
\hline & MORATILLA & 400 & 1.000 & & & & & & 1.400 \\
\hline & PARLA & 800 & & & & & & & 800 \\
\hline & PASTRANA & 1.600 & & & & & & & 1.600 \\
\hline & PEÑALVER & - & 867 & & 250 & 60 & & & 1.177 \\
\hline & POZUELO & 720 & & & & & & & 720 \\
\hline & QUISMONDO & 650 & & & & & & & 650 \\
\hline & ROZAS & 600 & & & & & & & 600 \\
\hline & $\begin{array}{l}\text { SAN AGUSTÍN } \\
\text { DE GUADALIX }\end{array}$ & 2.200 & & & & & & & 2.200 \\
\hline & $\begin{array}{l}\text { SAN SEBASTIÁN } \\
\text { DE LOS REYES }\end{array}$ & $\bullet$ & & & $\bullet$ & & & & \\
\hline & $\begin{array}{l}\text { SANTA CRUZ DE } \\
\text { RETAMAR }\end{array}$ & 300 & & & & & & & 300 \\
\hline & SERRANILLOS & 250 & & & & & & & 250 \\
\hline & $\begin{array}{l}\text { TORREJÓN DE } \\
\text { VELASCO }\end{array}$ & 1.100 & & & & & & & 1.100 \\
\hline & VALDECONCHA & 940 & & & & & & & 940 \\
\hline & \multirow{2}{*}{ VALLECAS } & 1.715 & & & & & & & 3.430 \\
\hline & & 1.715 & & & & & & & \\
\hline & VICÁLVARO & 950 & & & & & & & 950 \\
\hline & \multirow{2}{*}{ VILLAVERDE } & 650 & & & & & & & 870 \\
\hline & & 220 & & & & & & & \\
\hline & YEBRA & 873 & 1.667 & 60 & & & & & 2.600 \\
\hline
\end{tabular}

Fuente: elaboración propia a partir de las Respuestas generales del Catastro de Ensenada. 


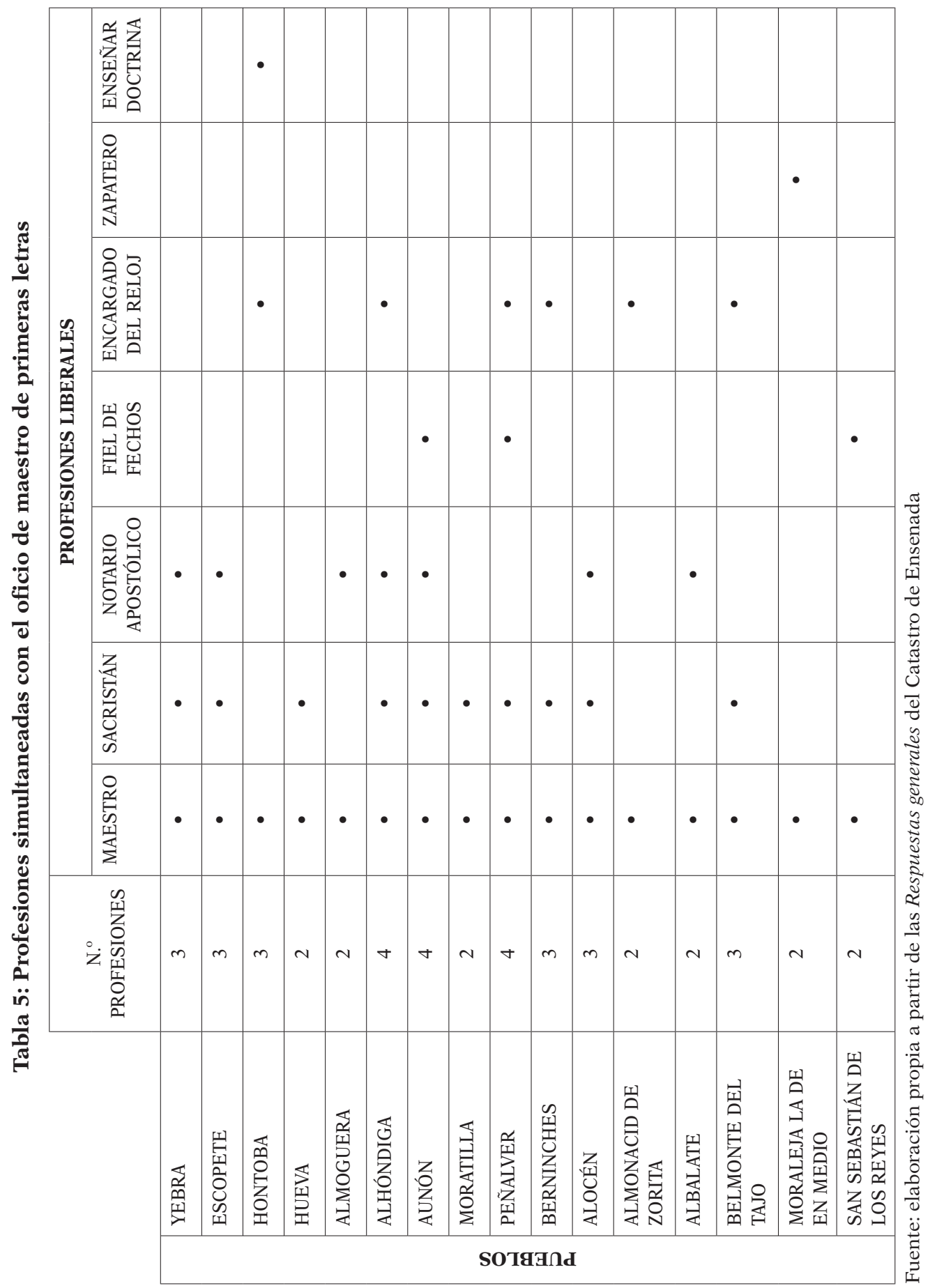




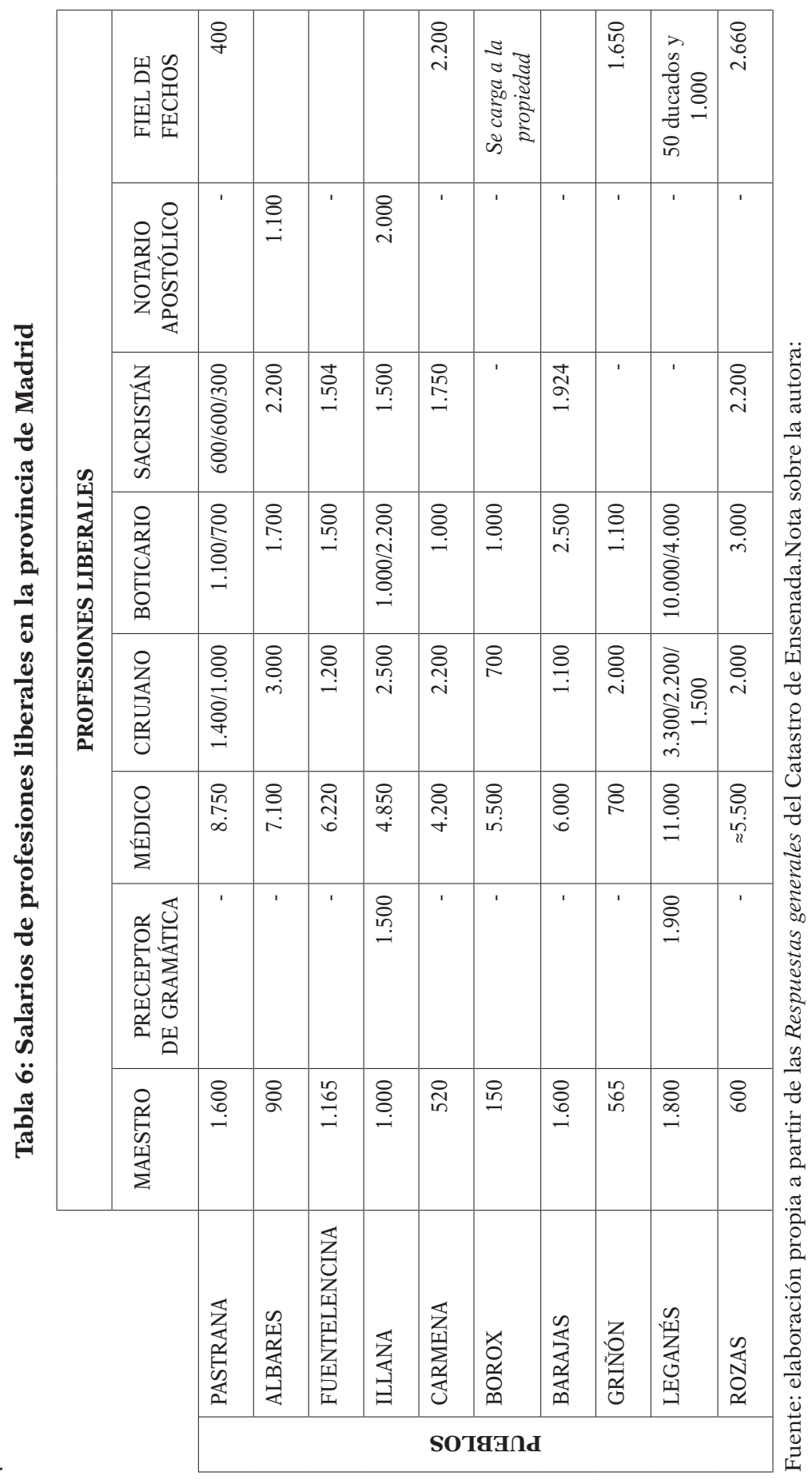




\section{Nota sobre la autora:}

Nuria GonzÁlez Barrero es graduada en Educación Primaria, con la especialidad de inglés, y Máster en Enseñanza Bilingüe; ambas titulaciones acreditadas por la Universidad Rey Juan Carlos de Madrid. Actualmente, trabaja en un Centro Público de Enseñanza Infantil y Primaria de la Comunidad de Madrid. Investiga temas relacionados con Historia de la Educación en la segunda mitad del siglo XVIII en el Departamento de Ciencias de la Educación, el Lenguaje, la Cultura y las Artes, Ciencias Histórico-Jurídicas y Humanísticas y Lenguas Modernas en la Facultad de Ciencias Jurídicas y Sociales de la Universidad en la que se tituló.

Ha sido becaria en el Centro Nacional de Innovación e Investigación Educativa de Ministerio de Educación, Cultura y Deporte y becaria en la Universidad Rey Juan Carlos, con una beca de investigación del Ministerio de Educación, Cultura y Deporte para estudiantes en departamentos universitarios. Como resultado de esta beca, publicó un artículo que fue premiado como el mejor trabajo de investigación en la modalidad de Ciencias de la Educación por el Consejo Social de dicha Universidad. Ha realizado, también, una pequeña estancia de investigación en Téramo (Italia), ha publicado otros artículos en diversas revistas de impacto científico y ha participado en Congresos y Seminarios Nacionales e Internacionales, tanto como ponente, como asistente o como miembro del comité organizador. 